\title{
Child Care Centers, Child Care Vouchers, and Faith-Based Organizations
}

\author{
MONICA ROHACEK \\ GINA ADAMS \\ KATHLEEN SNYDER
}

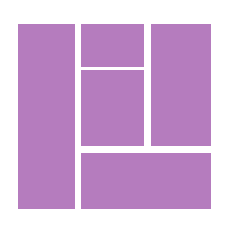

THE URBAN INSTITUTE 
Copyright (C) 2008. The Urban Institute. Permission is granted for reproduction of this report, with attribution to the Urban Institute.

The Urban Institute is a nonprofit, nonpartisan policy research and educational organization established in Washington, D.C., in 1968. Views expressed in this report are those of the authors and do not necessarily reflect the views of the Institute, its trustees, or its funders. 


\section{Contents}

Acknowledgments iv

Abstract vi

Research Questions and Methods

Data Sources 2

Analytic and Reporting Approach 3

Limitations of the Analysis 3

\section{Findings 4}

What Is the Role of Faith- Based Organizations in Providing or Supporting Center- Based Child Care? 5

To What Extent Do Centers Affiliated with Faith- Based Organizations Care for Children Receiving Child Care Vouchers? 11

Do Faith- Based Child Care Providers Face Any Particular Barriers to Working with the Voucher System? 14

Summary and Conclusions 18

Appendix A. Child Care Providers and the Child Care Voucher System: An Overview of the Urban Institute Research Project 22

Appendix B. Data Tables 24

Appendix C. Analytic Methods 32

Notes 34

References 36 


\section{Acknowledgments}

$\mathrm{T}$

his report is part of a larger study, Child Care Providers and the Child Care Voucher System, made possible by grants from the David and Lucile Packard Foundation; grant number 90YE0055 from the Administration for Children and Families, U.S. Department of Health and Human Services; the John D. and Catherine T. MacArthur Foundation (through the Urban Institute's Assessing the New Federalism project); and the Peppercorn Foundation. The contents are solely the responsibility of the authors. The contents do not represent the official views of the funding agencies, nor does publication in any way constitute an endorsement by the funding agencies.

The principal investigators for the study were Gina Adams and Matthew Stagner. Senior consultants included Ellen Kisker, Deborah Phillips, and Doug Wissoker. The survey component of the study was overseen by Matthew Stagner and directed and managed by Monica Rohacek at the Urban Institute. Mathematica Policy Research, Inc. (MPR) conducted the survey interviews and assisted with sampling and sample design. Key MPR staff included Audrey McDonald, Susan Sprachman, Amang Sukasih, Mark Dentini, Emily Dwoyer, Daniel Kasprzyk, Jennifer McNeill, Donna Mikolajewski, Debora Reese, and Kathy Sonnenfeld. Qualitative data collection for the study was directed by Gina Adams and managed by Kathleen Snyder; interviews and focus groups were conducted by Sara Bernstein, Debra Mekos, Monica Rohacek, and Kathleen Snyder. Data analyses were conducted by the authors as well as Ellen Kisker and Debra Mekos, and with the assistance of Sarah Adelman, Patti Banghart, Anna Danziger, Bonnie Gordic, Heidi Johnson, Joanna Parnes, Regan Main, Katie Mathews, and Laura Wherry. Spanish translation support was provided by Carlos Manjarrez, and the Spanish-language focus groups were facilitated by Stephanie Etienne, Vivian Vargas, and Irene Voisin.

The authors would like to thank Fiona Blackshaw, Ajay Chaudry, Ellen Kisker, Fredrica Kramer, Diana Jones Wilson, Ivelisse Martinez-Beck, Matthew Stagner, and Karen Tvedt for their helpful comments on earlier versions of this report. The authors extend a special thank you to the many state and local care administrators, caseworkers, and other experts who provided information for this study. We are also grateful to our panel of expert advisors who provided input on the study design. Finally, the authors 
owe a particular debt of gratitude to the many providers across our study sites who took the time to share their experiences and expertise with us.

This report is supported in part by the Urban Institute's Assessing the New Federalism project, a multiyear effort to monitor and assess the devolution of social programs from the federal to the state and local levels. In collaboration with Child Trends, the project studies child and family well-being. Assessing the New Federalism is currently supported by The Annie E. Casey Foundation and the John D. and Catherine T. MacArthur Foundation. 


\section{Abstract}

$\mathrm{R}$

elatively little is known about the role of faith-based organizations in the delivery children receiving publicly funded child care subsidies. Relying on a blend of quantitative and qualitative data, this report examines the relationship between child care centers and faith-based organizations in five counties across the United States. The data show that faith-based organizations play an important part in our child care system, though their role varies across and within counties. The data also show a substantial share of centers reporting affiliations with faith-based organizations are serving children whose fees are subsidized through child care vouchers, typically at similar rates as other centers. Further, interviews with experts and faith-based child care providers in these counties suggest there are few barriers to working with voucher programs that stem specifically from a center's faith affiliation. Respondents did suggest, however, that some faith-based centers may be more likely than other centers to have certain characteristics that affect their willingness to care for children receiving vouchers. These include such factors as not having the administrative capacity to manage subsidy procedures, which can act as a barrier to participation, and whether a center has a mission or goal of serving low-income families, which can facilitate participation. 


\section{Child Care Centers, Child Care Vouchers, and Faith-Based Organizations}

$\mathrm{T}$ he role of faith-based organizations (FBOs) in the delivery of social services is an area of increasing public interest. While there is some evidence that FBOs are an important component of the child care market (Bogle 2001a; Kinukawa, Guzman, and Lippman 2004; Neugebauer 2000; Ragan, Monteil, and Wright 2003; Witte and Queralt 2005), policymakers, researchers, advocates, and others need more information about the characteristics of faith-based child care providers, the share of the child care market they represent, and how willing they are to care for children receiving child care vouchers. And, although there appear to be few, if any, direct policy barriers to faith-based child care providers accepting children whose fees are subsidized through vouchers - as parents have been allowed to use their vouchers in sectarian settings for many years - there has been little research exploring that assumption.

\section{Research Questions and Methods}

This report provides insights into these important issues by examining three research questions in five counties across the United States.

1. What is the role of faith-based organizations in providing or supporting center-based child care?

2. To what extent do centers affiliated with faith-based organizations care for children receiving child care vouchers?

3. Do faith-based child care providers face any particular barriers to working with the voucher system? 


\section{Data Sources}

The data for this report come from an Urban Institute study, Child Care Providers and the Child Care Voucher System, which examined the child care market and the effect of voucher programs on child care providers in five communities. An overview of Child Care Providers and the Child Care Voucher System is included in appendix A. Although the role of faith-based organizations in child care was not the primary focus of the study, some quantitative and quantitative data were collected to allow for exploration of this topic. The data for this report have two major components:

- Quantitative data are from a telephone survey conducted in 2003 with a representative sample of child care centers and licensed family child care providers. The sampling population included centers and licensed homes that serve preschool-age children (age 5 and under, not yet in school); offer services to preschool-age children for at least 40 hours a week; and are funded through parent fees, state child care voucher programs, the Abbott Preschool Program in New Jersey, or General Child Care/State Preschool funding in California. The results reported here are based only on the data collected from centers, of which there were 407 in the sample. ${ }^{1}$

- Qualitative data on faith-based issues are from interviews with state and local subsidy administrators as well as a range of other key respondents. The other respondents included at least two faith-based providers in each site, a national expert on these issues, and local informants familiar with faith-based child care in their communities. We also gathered information from faith-based providers through the focus groups conducted with providers for the overall study.

These data for Child Care Providers and the Child Care Voucher System were collected from five counties in four states:

- Jefferson County, AL (Birmingham);

- San Diego County, CA;

- Monterey County, CA;

- Hudson County, NJ (Jersey City); and

- King County, WA (Seattle).

Four of the five counties were selected from 17 sites that were part of the Urban Institute's 1999 child care subsidy case studies. Monterey County was selected from a set of additional counties in California that were of interest to a project funder. All five counties were selected to ensure variation in early childhood system characteristics such as child care voucher reimbursement rates, types of agencies administering voucher programs and their implementation practices, availability of prekindergarten programs, use of contract funding mechanisms for subsidies, stringency of licensing regulations, and 
the proportion of subsidized families relying on different types of care. Beyond varying according to early childhood system characteristics, the counties also differ on certain demographic characteristics such as population size, income, and poverty rates.

\section{Analytic and Reporting Approach}

Quantitative findings in this report are presented for each of the five study counties individually. This is because there is variation in results across the five study counties, and because the counties do not collectively represent a useful geographic or conceptual group. Survey responses are weighted to account for the probability of selection into the sample and for survey nonresponse. ${ }^{2}$ Analysis was conducted using Stata survey commands. These survey commands incorporate information about the sample design (including weights, stratification, and a finite population correction factor) into the calculation of point estimates, standard errors, and related confidence intervals and tests for significant differences.

Because this is an exploratory study in which the goal is to understand the full range of possible differences between and across counties, we use a threshold of $p<.10$ for tests for significant differences. Compared with more typically used thresholds (such as $p<.05$ or $p<.01), p<.10$ reduces the risk of not finding a difference when a difference actually exists in the population. ${ }^{3}$ Two types of tests for significant differences across counties are reported. First, we report the results of a joint test for any significant differences across the five counties. Second, we report the results of pairwise tests of differences in each county to identify the counties between which there were differences. To simplify reporting of results, the text of the report omits as many statistical details as possible. Complete tabular results with statistical details can be found in appendix B, and additional information about the analytic methods can be found in appendix $C$.

\section{Limitations of the Analysis}

Despite the rich variation in characteristics across our sites, it is important to note that the survey data are only representative of the counties from which they were collected. Although the survey results presented in this report can be generalized to the population of centers meeting the sampling criteria in each county, there is a relatively large amount of statistical uncertainty around some of the estimates. This uncertainty should be considered when generalizing from the sample estimates presented in the report to the population of providers in each county. ${ }^{4}$ The amount of statistical uncertainty is quantified by the confidence intervals shown in each figure and table. The intervals indicate the range within which we can be relatively certain the true population value falls and are set at a 90 percent confidence level to correspond with the threshold used for tests of significant differences. ${ }^{5}$ 
Similarly, the qualitative results reflect the beliefs of the individuals we interviewed and are not necessarily representative of the opinions of other providers or experts in the study communities or states. Without complementary survey results, it is also not possible to assess the prevalence of the issues raised by qualitative respondents. Despite these limitations, the qualitative findings offer important, if unrepresentative, details about some experiences of faith-based providers with the subsidy system.

\section{Findings}

The first challenge in understanding the role of faith-based organizations (FBOs) in child care is to define the kinds of relationships that FBOs have with child care programs. These relationships can vary widely. On one end of the continuum, some centers obtain physical space from an FBO but otherwise have no other connections with the FBO. At the other end of the continuum, there are centers providing religious instruction and being operated by an FBO as well as receiving funding, administrative or accounting support, and physical space from the FBO. As one California respondent noted, "They're all so different ... there is not one cookie cutter model for faith-based [child care] programs."

Given the complexity of the relationships between child care programs and FBOs, there does not appear to be consensus on a single definition of "faith-based" child care (Kramer et al. 2005; Ragan et al. 2003). In this analysis, we provide information on three different types of relationships between FBOs and child care centers. These relationships, as defined by our survey items and research questions, are described below.

- Faith-affiliated child care programs are those that report an affiliation with a church, synagogue, temple, mosque, or other faith-based organization or group. Past research has typically distinguished between centers operated by FBOs and those that are housed in buildings belonging to FBOs but are independently operated (Bogle 2001b). In this analysis, we assume that centers reporting affiliations with FBOs generally correspond to centers that have been classified in other research as directly or indirectly operated by FBOs. ${ }^{6}$

- Faith-housed child care programs are located in buildings that belong to a church, temple, synagogue, mosque, or other FBO. These child care centers may be either affiliated or unaffiliated with the FBOs that are housing them. We assume that unaffiliated child care centers housed in buildings belonging to FBOs are operated independently from the FBOs. 
- Faith-infused child care centers provide religious instruction or include organized prayers or worship services. These centers may be either affiliated or unaffiliated with an FBO and they may, or may not, be housed in buildings that belong to FBOs.

These three categories - faith-affiliated, faith-housed, and faith-infused-are not mutually exclusive. Center directors can report being in any, all, or none of the categories. Although all three types of associations are important and will be described at least briefly, the analysis in this report focuses in greatest detail on faith-affiliated providers.

\section{What Is the Role of Faith- Based Organizations in Providing or Supporting Center- Based Child Care?}

This research question concerns the role of FBOs in center-based child care markets in our five study communities. We focus first on how many center directors reported affiliations with FBOs (faith-affiliated). The discussion of faith-affiliated child care is followed by results on how many directors reported being housed by FBOs (faith-housed) and then how many center directors reported providing religious instruction or organized prayer or worship services (faith-infused). Finally, this section of the report on the prevalence of faith-based child care concludes with a discussion of how frequently center directors reported having any of these three associations with a faith community.

\section{Faith- affiliated child care centers}

Our first approach to understanding the role of FBOs in the provision of child care services examines centers reporting affiliations with FBOs. These are child care centers that report an affiliation with a church, synagogue, temple, mosque, or other FBO or faith group, including an affiliation with a private religious school. As mentioned earlier, we assume that a report of faith-affiliation by center directors roughly corresponds to being operated, either directly or indirectly, by the FBO. The data allow us to examine several characteristics of faith-affiliated centers including the overall proportion of centers reporting an affiliation with an FBO; how many FBO affiliations are with private religious schools; and the kinds of support centers receive from nonschool FBOs.

\section{Prevalence of faith-affiliated child care centers}

As shown in figure 1, a substantial minority of centers in each study site reported an affiliation with an FBO, though the level varied from one county to another. The highest proportion of center directors reporting an affiliation with an FBO was 44 percent in Jefferson County. This was followed by San Diego and Monterey counties, in which 35 percent and 25 percent of center directors reported an affiliation with an FBO. The lowest proportions were 16 and 17 percent, respectively, in Hudson and King counties. Not all differences across the counties were statistically significant; the differences between Jefferson and San Diego counties, and between Hudson and King counties, were not sig- 
nificant. (See appendix table B1 for complete tabular results and additional statistical details).

FIGURE 1. Child Care Centers Reporting an Affiliation with a Faith- Based Organization, by Affiliation with a Private Religious School or Nonschool Faith- Based Organization, 2003

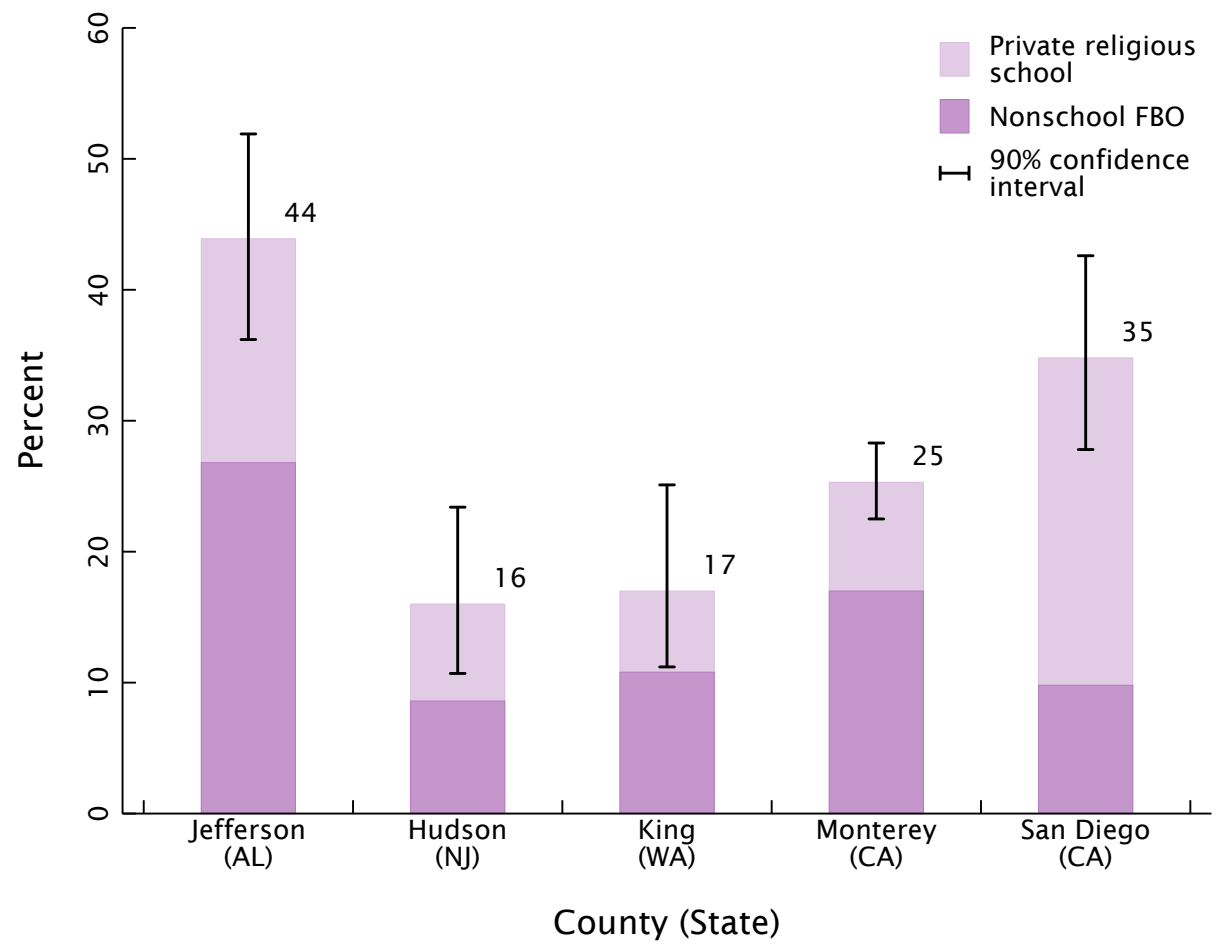

Source: The Urban Institute, 2008.

$\mathrm{FBO}=$ faith- based organization

Notes: See appendix tables B1 and B2 for tabular results and additional statistical details.

Confidence intervals account for the sample design and use a finite population correction factor.

Percent labels and confidence intervals refer to total bar heights (affiliation with any type of faith- based organization).

\section{Affiliation with private religious schools versus nonschool FBOs}

Child care centers affiliated with private religious schools may differ in important ways from other faith-affiliated child care centers (including being subject to different standards and regulations than other child care programs). Therefore, figure 1 and appendix table B1 also present the faith-affiliated centers in terms of the share affiliated with private religious schools versus the share affiliated with nonschool FBOs.7 Again, there were some differences across counties. Jefferson and San Diego counties had the highest share of centers affiliated with private religious schools, at 17 and 25 percent, respectively. In the other counties, between 6 and 8 percent of all centers were affiliated with private religious schools. 
Another approach to this question is to look just at those centers affiliated with FBOs and to examine the percent reporting affiliations with private religious schools versus reporting affiliations with nonschool FBOs. In Jefferson and Monterey counties, less than half of centers with any faith affiliation were connected to private religious schools. In contrast, more than half of faith-affiliated centers in San Diego County were affiliated with private religious schools. The estimates in Hudson and King counties look more like Jefferson than San Diego County. However, because the samples of faith-affiliated centers in Hudson and King counties were small relative to the overall population of centers, we cannot, with adequate certainty, describe these counties in terms of whether more or less than half of faith-affiliated centers are connected to private religious schools. (See appendix table B2 for complete tabular results and additional statistical details.)

\section{Forms of support for centers affiliated with nonschool FBOs}

Centers affiliated with FBOs may receive different types and levels of support from the organization with which they are affiliated. Centers directors reporting an affiliation with a nonschool FBO were asked if they received any of the following through their affiliation: cash funding, administrative or accounting support, and free or discounted rent or utilities. The sample sizes for centers affiliated with nonschool FBOs are small, making it difficult to generalize from the sample estimate to the population of centers except in terms of estimates with large ranges. The ranges in Hudson and King counties are too large to be meaningful. For the remaining three counties, we discuss general trends below, primarily presenting the range of the 90 percent confidence interval and only emphasizing point estimates when the related confidence interval is relatively small. (Tabular results and additional statistical details for all five counties are presented in appendix table B3).

- Cash support. In Jefferson, Monterey, and San Diego counties, cash funding appeared to be the least common form of support for centers affiliated with nonschool FBOs. In Jefferson and Monterey counties, less than one-third of centers affiliated with a nonschool FBO received cash support from the FBO. In San Diego County, less than half of nonschool FBO-affiliated centers received cash funding from the FBO.

- Administrative or accounting support. There is more variation across sites in whether centers received administrative or accounting support from the nonschool FBOs with which they were affiliated. Such support is quite common in Monterey County, where 88 percent of centers affiliated with a nonschool FBO reported this type of support. San Diego and Jefferson had a smaller percentage of centers receiving administrative or accounting support from the FBO with which they were affiliated; an estimated one- to two-thirds of nonschool faith-affiliated centers in San Diego County (and less than half of nonschool faith-affiliated centers in Jefferson County) received administrative or accounting support from the FBO. 
- Free or discounted rent or utilities. Assistance with rent or utility costs was relatively common among centers affiliated with nonschool FBOs in Monterey County, where 64 percent of center directors affiliated with a nonschool FBO reported such assistance. Compared with Monterey County, the share of centers receiving free or discounted rent or utilities was lower in the Jefferson County sample and higher in the San Diego County sample. Because the confidence intervals for these estimates overlap substantially, however, we cannot conclude the observed differences were not the result of sampling error.

\section{Other ways child care centers connect with faith- based organizations}

Even when they are not affiliated with (directly or indirectly operated by) an FBO, child care programs may have other types of connections with FBOs (such as residing in space belonging to a church) or be thought of as "faith-based" because they include religious instruction or organized prayers or worship services (faith-infused). The prevalence of these types of centers is presented below, along with information about how being faithhoused or faith-infused overlaps with faith-affiliation.

\section{Faith-housed child care centers}

One way that FBOs assist child care centers without being involved in day-to-day operations is by providing building space, either at fair-market value, for free, or at reduced cost. For all the centers in the sample, the survey asked directors whether their program was housed in a building that belonged to a church, temple, synagogue, mosque, or other faith-based organization. As shown in the medium-shaded bars of figure 2, the proportion of all centers that reported being faith-housed ranged between roughly 20 and 40 percent across the sites. (Complete tabular results and additional statistical details can be found in appendix table B4.)

Not surprisingly, centers affiliated with an FBO appeared substantially more likely than other centers to be faith-housed. As shown in the lightest bars of figure 2, most (but not all) faith-affiliated centers reported being housed in a building that belonged to the FBO. The percent ranged from 79 to 97 , depending on the county.

It is also useful to recognize, however, that some centers not affiliated with an FBO were housed in a building that belonged to a church, temple, synagogue, mosque, or other FBO. The darkest bars in figure 2 show the rates at which non-faith-affiliated centers were faith-housed. In King, Monterey, and San Diego counties, around 5 percent of centers not affiliated with an FBO were faith-housed. In Hudson County, a significantly higher share of non-faith-affiliated centers (17 percent) was faith-housed. Jefferson County fell in the middle, at 10 percent, but because of the ranges on the confidence intervals, we cannot conclude that the observed differences between Jefferson and the other counties are not the result of sampling error. 
FIGURE 2. Child Care Centers that Are Faith- Housed, among All Centers and by Reported Affiliation with a Faith- Based Organization, 2003

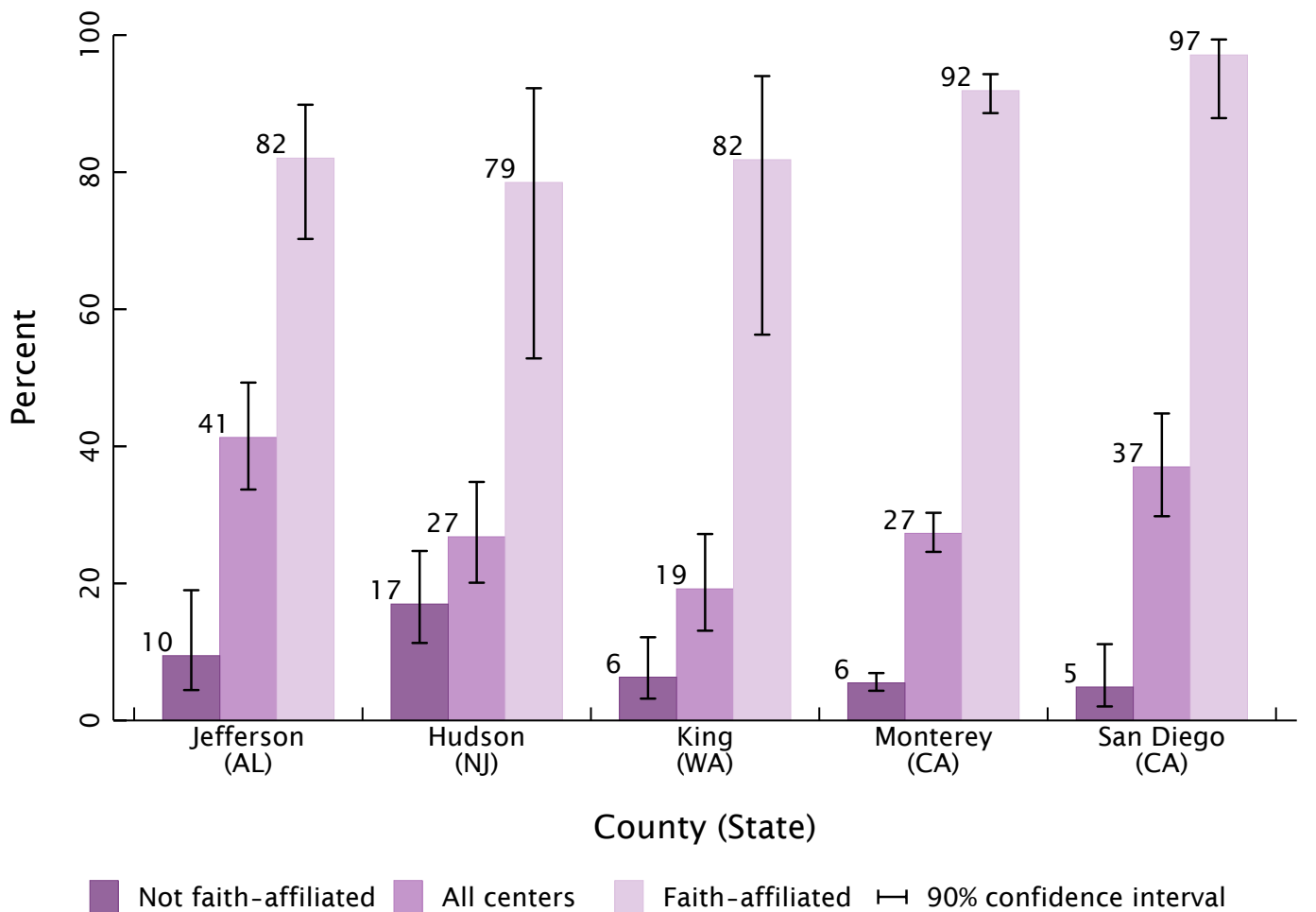

Source: The Urban Institute, 2008

Notes: See appendix table B4 for tabular results and additional statistical details.

Confidence intervals account for the sample design and use a finite population correction factor.

\section{Faith-infused child care centers}

The final dimension of faith-based child care that we explore is the proportion of centers that are faith-infused. We define faith-infused as offering religious instruction or organized prayer or worship services. Figure 3 presents the percent of center directors reporting their programs included these characteristics of faith-infusion. Looking first at how many centers overall were faith-infused (the medium-shaded bars), we again find significant variation across sites - from 54 percent of centers in Jefferson County, to between 25 and 28 percent in Monterey and San Diego counties, to 11 to 14 percent in Hudson and King counties. Except between Hudson and King counties, and Monterey and San Diego counties, the differences across counties were statistically significant. (See appendix table B5 for tabular results and additional statistical details.)

Figure 3 also shows the relationship between faith-infusion and affiliation with an FBO. Although religious instruction is common for faith-affiliated centers, not all faithaffiliated centers provide religious instruction or organized prayer or worship services. 
It is also notable that the sample in three sites included at least some centers not affiliated with FBOs that did offer religious instruction or organized pray or worship services. In most counties, faith-infusion in centers affiliated with FBOs was relatively common, while faith-infusion in centers not affiliated with FBOs was rare.

In Hudson, King, Monterey, and San Diego counties, as many as 100 percent, but as few as 64 percent, of faith-affiliated centers were faith-infused. In contrast, less than 5 percent of centers not affiliated with FBOs in these counties were faith-infused. The trend in Jefferson County is similar in that faith-affiliated centers were more likely than non-faith-affiliated centers to be faith-infused. However, Jefferson County is also notably different from the others because around 40 percent of centers not affiliated with an FBO reported providing religious instruction or organized prayer or worship services.

\section{FIGURE 3. Child Care Centers that Are Faith- Infused, among All Centers and by Reported Affiliation with a Faith- Based Organization, 2003}

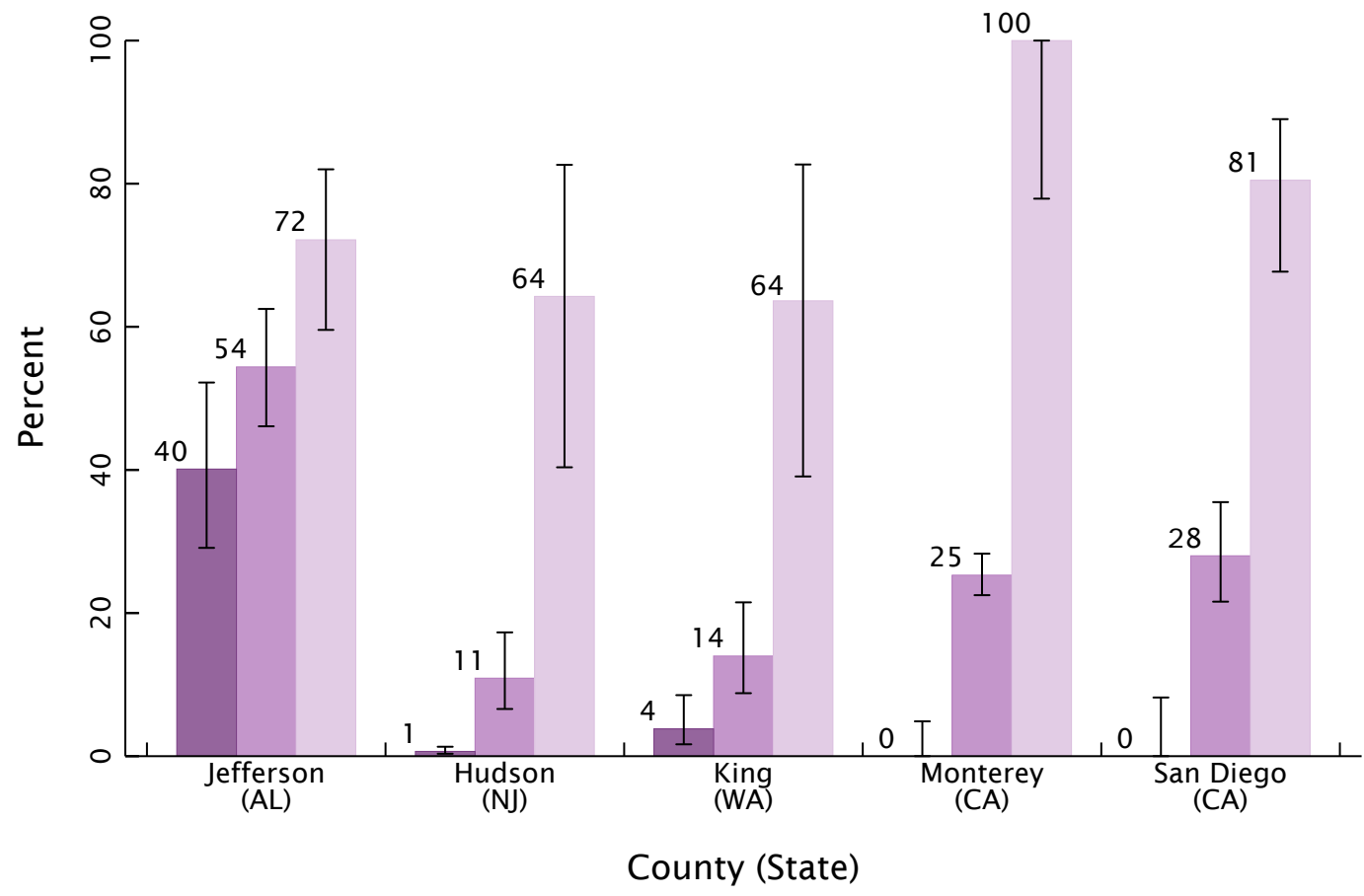

Not faith- affiliated

All centers

Faith-affiliated $\longmapsto 90 \%$ confidence interval

Source: The Urban Institute, 2008.

Notes: See appendix table B5 for tabular results and additional statistical details.

Confidence intervals account for the sample design and use a finite population correction factor. 


\section{An overall picture: any faith connections}

Finally, it is useful to examine how many center directors in the five counties reported any connections with religion or FBOs - that is, being faith-affiliated, faith-housed, or faith-infused. Looking at the picture in this way, we find that the faith community was a significant player in the center-based child care market in each of the five counties we studied, though the extent of involvement varied across sites. Specifically, as shown in figure 4 and appendix table B6, approximately two-thirds of centers in Jefferson County had one or more of these connections to the faith community. In contrast, approximately one-quarter to one-third of centers in the other counties had one or more types of connections to the faith community.

FIGURE 4. Child Care Centers Reporting They Are Faith- Affiliated, Faith- Housed, or Faith- Infused, 2003

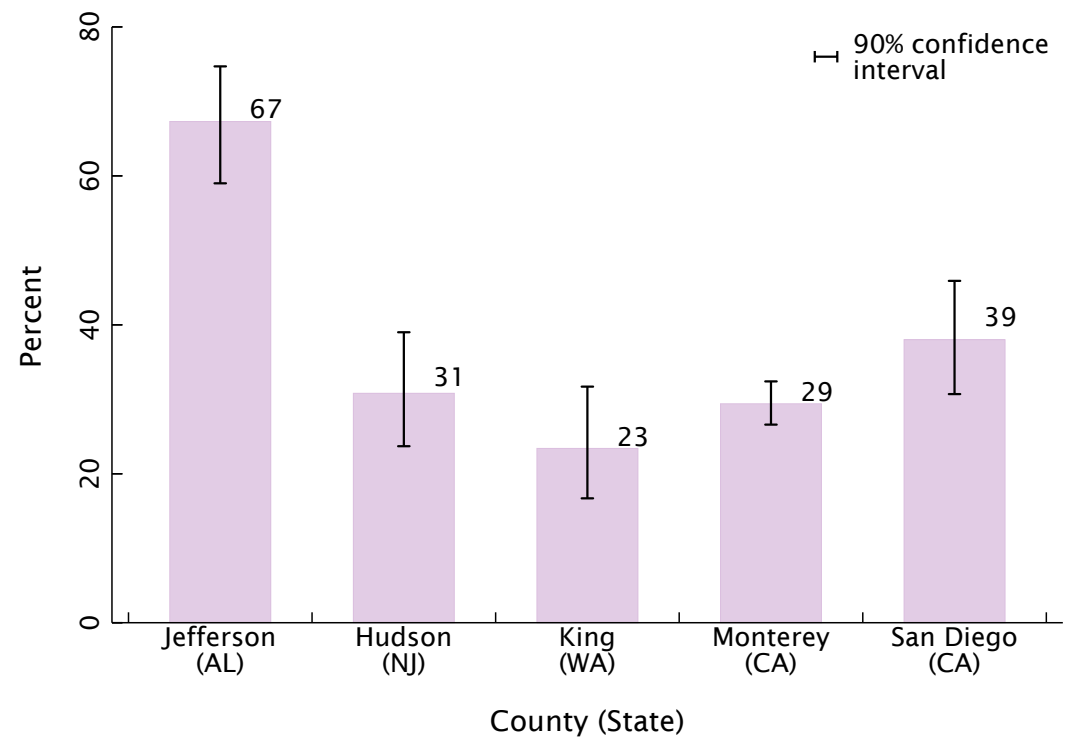

Source: The Urban Institute, 2008.

Notes: See appendix table B6 for tabular results and additional statistical details.

Confidence intervals account for the sample design and use a finite population correction factor.

\section{To What Extent Do Centers Affiliated with Faith- Based Organizations Care for Children Receiving Child Care Vouchers?}

The second research question examines how often faith-affiliated child care providers serve children whose fees are subsidized with vouchers. Policymakers concerned about ensuring FBOs have a role in the delivery of social services are most likely to be interested in understanding whether child care centers operated by FBOs (either directly or 
indirectly) are able to access public funding. As a result, this analysis focuses on voucher program involvement among centers reporting an affiliation with an FBO. As described earlier, these are the centers most likely to be operated, at least in part, by an FBO.

Although there are numerous public and private sources of subsidies for child care, this study specifically focuses on vouchers funded through Child Care and Development Block Grant (CCDBG). ${ }^{8}$ The CCDBG is also referred to as the Child Care and Development Fund (CCDF) and is one of the largest sources of public funding for child care. Under the CCDF, most assistance is administered in the form of a voucher that allows eligible parents to choose any legally operating child care center or individual provider, including faith-based programs. In some places, vouchers may be referred to as "certificates." There are many different ways to define whether child care programs are involved with the voucher system. Here we categorize centers according to whether, at the time of the interview or in the six months before the interview, they were caring for at least one child receiving a voucher through a program funded by the CCDF. ${ }^{9}$

\section{What proportion of faith- affiliated centers serves children receiving vouchers?}

A substantial percentage of faith-affiliated centers in each of our five sites was involved with the voucher system. The darker bars in figure 5 show the share of faith-affiliated centers that were serving children receiving vouchers, including both centers affiliated with private religious schools and centers affiliated with nonschool FBOs.

Figure 5 indicates that a majority of faith-affiliated providers in all five counties were currently caring for at least one child with a voucher or had done so in the previous six months. The highest rates were in King County, in which all the sampled faith-affiliated centers were serving children whose fees were subsidized through a voucher, and in Hudson County, where an estimated 90 percent of faith-affiliated centers did so. The estimated rates in the other counties were 74 percent in Monterey, 69 percent in Jefferson, and 62 percent in San Diego. (Tabular results and additional statistical details for all five counties are presented in appendix table B7.)

\section{Does the rate at which faith- affiliated centers serve children with vouchers differ from the rate among centers that are not faith- affiliated?}

Comparing voucher involvement among faith-affiliated and non-faith-affiliated centers (non-faith-affiliated programs include those that are faith-housed or faith-infused, as well as those with no connections to FBOs), we find that patterns of differences varied across sites. As shown in the lighter bars in figure 5, three sites (Hudson, King, and San Diego counties) did not have significant differences in the share of faith-affiliated and non-faith-affiliated centers currently or recently caring for at least one child receiving a voucher. In Monterey County, faith-affiliated centers were significantly more likely than non-faith-affiliated enters to be involved with the voucher system (74 percent compared with 62 percent). In Jefferson County, faith-affiliated centers were less likely than other 
centers to be caring for at least one child receiving a voucher (69 percent compared with 96 percent).

FIGURE 5. Child Care Centers Currently or Recently Caring for at Least One Child with a Child Care and Development Block Grant-Funded Voucher, by Reported Affiliation with a Faith- Based Organization, 2003

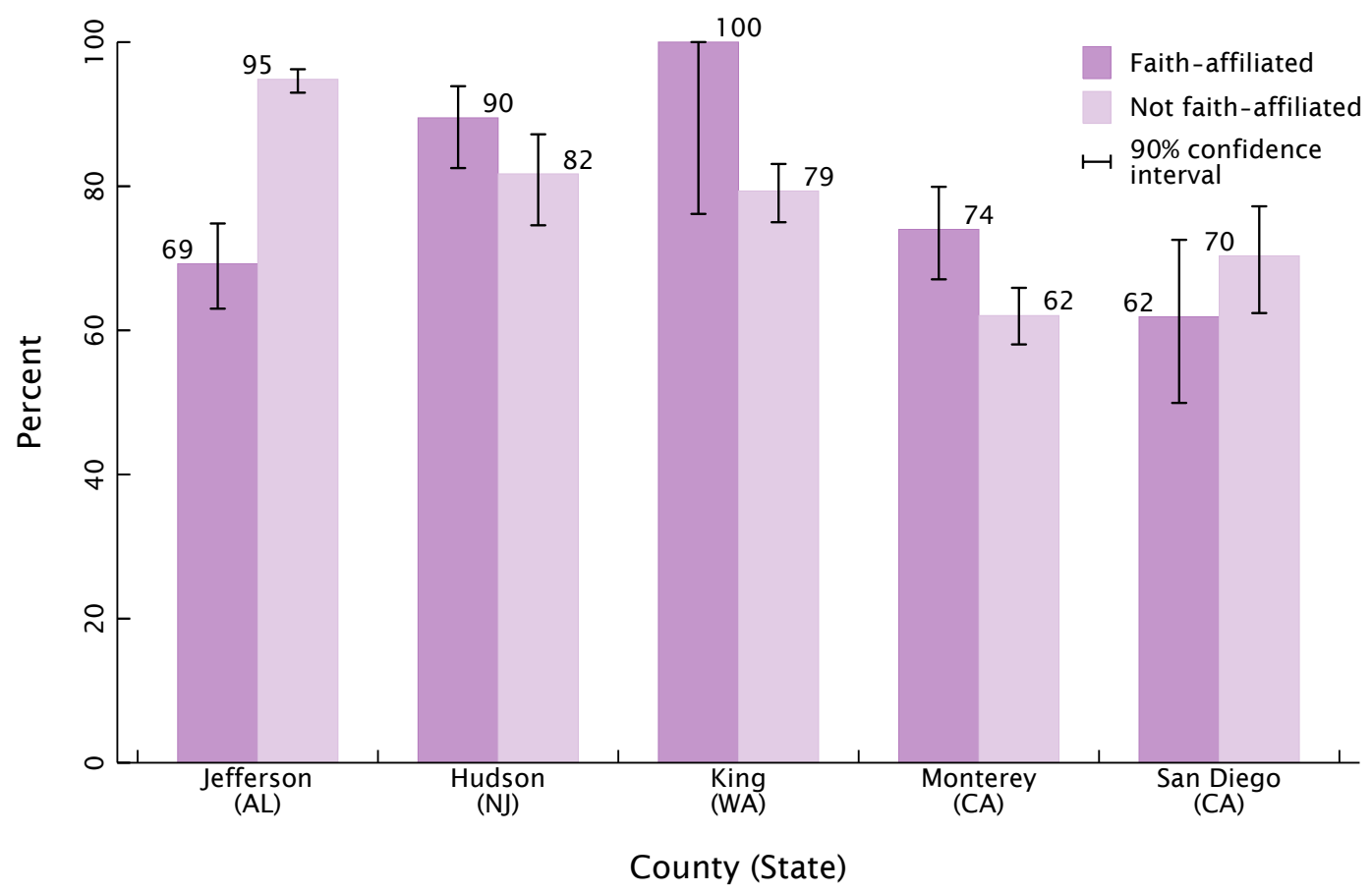

Source: The Urban Institute, 2008.

Notes: See appendix table B7 for tabular results and additional statistical details.

Confidence intervals account for the sample design and use a finite population correction factor.

Although not funded by the Child Care and Development Block Grant, providers caring for children receiving

vouchers through a program funded by the City of Seattle were also counted.

"Recently" is defined as in the six months before the suvey interview.

One explanation for the differential rate of voucher involvement among faithaffiliated and non-faith-affiliated centers in Jefferson County could be related to differences among centers that are part of private religious schools also serving school-age children versus those that are connected to other (nonschool) FBOs. To the extent that child care centers in private schools serve specialized populations, they may be less likely to serve families that are eligible for, or receiving, means-tested subsidies. A test of this hypothesis in Jefferson County (figure 6) shows that most of the differential rate of voucher involvement among faith-affiliated and non-faith-affiliated centers was because of a substantially lower rate of voucher involvement among centers affiliated with private religious schools. ${ }^{10}$ 
Figure 6 shows that 46 percent of centers affiliated with private religious schools in Jefferson County were currently or recently caring for at least one child with a voucher, compared with 84 percent of centers affiliated with a nonschool FBO and 95 percent of centers not affiliated with an FBO. Although the data collection protocols for this study did not specifically address this issue, one interview respondent noted that another explanation for these different patterns of voucher involvement may be that uninvolved programs offer subsidies or scholarships through other sources, such as a church endowment or other funds from the FBO.

FIGURE 6. Centers Currently or Recently Caring for a Child with a Child Care and Development Block Grant-Funded Voucher, Jefferson County, AL, 2003

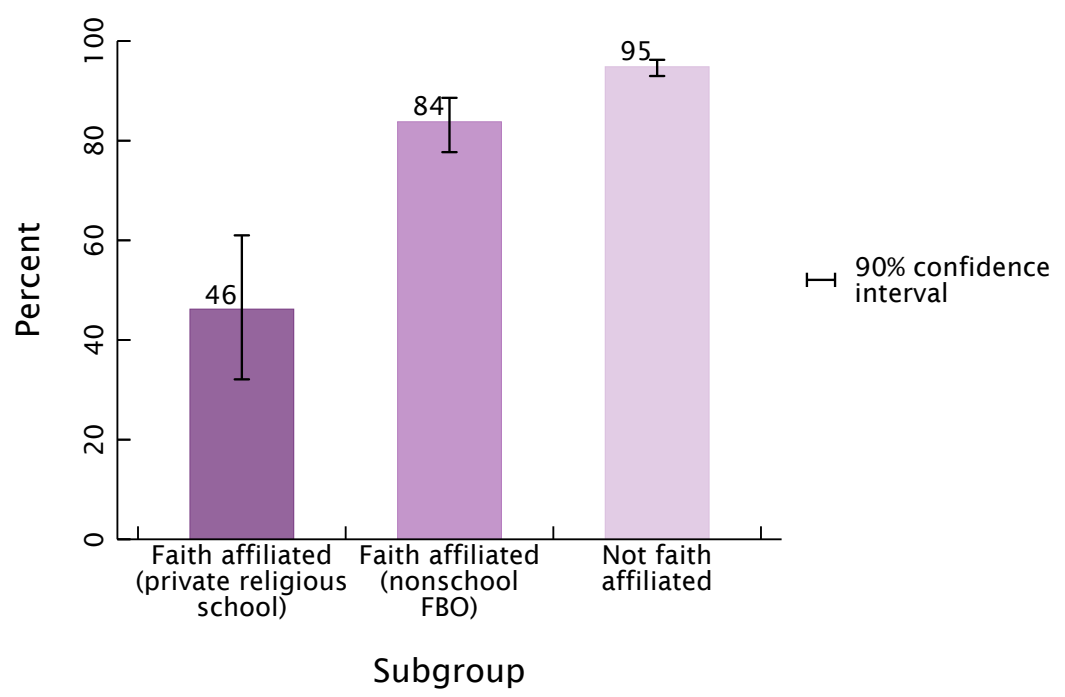

Source: The Urban Institute, 2008.

$\mathrm{FBO}=$ faith- based organization

Notes: See appendix table B7 for tabular results and additional statistical details.

Confidence intervals account for the sample design and use a finite population correction factor.

"Recently" is defined as in the six months before the suvey interview.

\section{Do Faith- Based Child Care Providers Face Any Particular Barriers to Working with the Voucher System?}

The final research question examined in this study is whether faith-based child care providers appear to face any barriers to voucher involvement. Although federal regulations require that vouchers be available for use with any legally operating child care provider including faith-based programs, states have a great deal of flexibility in establishing specific rules under the CCDF including family eligibility limits and co-payment amounts; health, safety and programmatic requirements providers must meet to care for children 
receiving vouchers; and administrative procedures and requirements. As a result, there is concern that certain rules or implementation practices may inadvertently present barriers to the participation of faith-based providers in the voucher system (White House 2001).

We explore this question using the qualitative data described earlier. Respondents were asked about issues related to faith-based providers, including whether these providers are affected differently by child care voucher policies and implementation practices, whether they face different requirements, and whether there are barriers they face in serving subsidized children. Responses to these questions are summarized below.

\section{Faith- based providers in these counties face few (if any) policy barriers to serving children whose fees are subsidized with vouchers}

Generally, there was consensus across respondents that few (if any) barriers in child care voucher policy or implementation practice prevent faith-based providers from caring for children receiving vouchers. This finding, which was reported by a range of respondents both inside and outside the faith-based community, seems consistent with the data presented earlier showing that a large share of faith-based providers across all the study counties were involved with the voucher program. Further, respondents report that, generally, there are no special requirements or any special voucher policies or implementation practices that affect faith-based providers differently because of their faithbased status.

The one exception to this finding was Jefferson County, where faith-based centers can choose to be exempt from state child care licensing laws. ${ }^{11}$ While not all faith-based providers in Jefferson County claim this exemption, before April 2003, those who wished to opt out were required to certify they met licensing standards before they could receive voucher payments. Although this requirement for voucher payments was no longer in effect at the time of our visit and the provision was not raised as a barrier to subsidy participation by most of our respondents, two faith-based providers in the focus groups discussed their concerns about this provision not allowing "total independence." As one of them said, "We didn't want to be subjected to those stipulations, so ... we just opted to stay away." In addition, some Jefferson County survey respondents reported they were not currently caring for children receiving vouchers because they were concerned about meeting licensing standards.

\section{Some faith- based providers may be concerned about government intrusion, and some may (mistakenly) perceive restrictions on religious education}

Some respondents reported that certain faith-based providers are concerned about government intrusion and might resist accepting children with vouchers because of this concern. ${ }^{12}$ As one provider said, "To ask the faith community to embrace a state-funded program is very difficult .... There [are] a lot of trust issues and [there is] a ... 'we don't 
want to cross that [separation of church and state] line' attitude." However, respondents noted that this issue of government intrusion is also of concern to other, non-faith-based providers. As a consequence, it is difficult to evaluate whether and how much this issue differentially affects faith-based centers versus other providers.

The concern over keeping the "state" out of faith-based child care programs appears somewhat greater in Alabama, where at least one respondent suggested that some faithbased providers are less willing than others types of providers to care for children receiving vouchers. This respondent pointed out that faith-based providers have "tended to want to stay away from anything that ... may indicate that the state would have anything to do with ... what they teach." Although our informants were not aware of any prohibitions on religious teaching, a few respondents suggested that some faith-based centers incorrectly assumed they would need to remove religious teaching from their program to serve children with child care vouchers.

There are, in fact, no restrictions on use of federal CCDF funds in programs that provide religious education, ${ }^{13}$ and none of the states in the study required faith-based providers to change the religious aspects of their program in order to receive payments through vouchers. ${ }^{14}$ Federal CCDF regulations specify that child care vouchers "may be expended by providers for any sectarian purpose or activity that is part of the child care services, including sectarian worship or instruction" (U.S. Department of Heath and Human Services 1998). Despite this language, several Jefferson County survey respondents reported they were not currently caring for children receiving vouchers for such reasons as, "We don't want anyone to have a say in what we do." Our respondents emphasized that this is only a barrier for some faith-based providers; the data that show a majority of faith-based programs are caring for children with vouchers confirm this impression among the key informants.

\section{Other issues may affect the involvement of faith- based providers with the child care voucher system}

As noted above, respondents reported that there are not any child care voucher policies or practices that affected faith-based providers differently than other providers solely because of their faith-based status. ${ }^{15}$ Nevertheless, several respondents did think that faith-based providers might be more likely to have certain characteristics that could affect (both positively and negatively) their willingness to serve children receiving vouchers. These issues are also relevant to the larger community of providers.

Degree of access to financial or administrative support may affect ability to work with voucher agencies

A number of respondents mentioned that financial and administrative capacity could affect the ability of faith-based providers to work with the voucher program - with those that had more financial or administrative capacity finding it easier to do what was necessary to serve children with vouchers, and those with less capacity, typically smaller 
organizations, finding it more challenging. This issue also came up in our other research on subsidies and providers, which suggested that-regardless of faith status-voucher policies and practices may differentially affect providers with different levels of access to administrative and financial support (Adams, Rohacek, and Snyder 2008).

For example, respondents noted that some faith-based providers have the financial or administrative support of their congregation or a larger religious organization (such as the Salvation Army). This support can help in a number of ways. Administrative support can assist center staff with the basic functions of working with the voucher agency (i.e., tracking attendance, filling out paperwork, managing finances, and so on). Financial support can help offset any cash-flow challenges associated with retrospective or late payments from the subsidy agency. For example, a faith-based provider in California said, "[We can] absorb that time [resulting from retrospective subsidy payments]; it doesn't affect us because we're so large."

Yet respondents also suggested that some faith-based providers have less administrative capacity than other centers, making it more challenging to navigate the subsidy system and more difficult to accept voucher-based subsidies. As one California respondent noted, "Most church-based [providers] don't have the administrative structure ... to help with all that paperwork stuff [in the voucher program]." Another California provider suggested that faith-based providers struggled more in managing finances, saying, "We're not the most educated in finances ... not the most experienced administrators; we just have a heart for children."

Some faith-based providers may also have limited financial resources, which can make issues such as late or inaccurate voucher payments more challenging. In addition, child care centers typically charge parent fees ahead of the time services are provided, while many voucher agencies make payments after the services are delivered, potentially presenting a cash flow problem for centers. The large faith-based provider in California who said that her program was not affected by retrospective payments also pointed out, "the smaller ones [faith-based programs], they have to make the payroll and ... they're afraid of all that ... running a month behind and not being paid." This respondent also described the financial challenges faced by some faith-based centers by saying, "Most faith-based centers are in the red and the congregations are supporting those centers as part of their ministry."

These issues are similar to problems faced by some secular providers-especially smaller providers - in working with the voucher system (see Adams et al. 2008). And, as discussed previously, the centers affiliated with nonschool FBOs in these counties vary in whether they have access to financial or administrative support from the FBO with which they are affiliated. These findings suggest that it is useful to consider characteristics of providers, beyond their faith status, that may limit or support their ability to enroll children receiving vouchers. 
"Service to community" focus may affect willingness to serve children receiving vouchers

Respondents pointed to one characteristic that may be more prevalent among faithbased providers and can affect their willingness to care for subsidized children. In particular, a number of respondents believed that a ministry-oriented mission (i.e., a focus on serving the community) can make faith-based providers more willing to be involved with the child care voucher program since it is an opportunity to serve low-income families. For example, one faith-based provider in Washington noted, "Faith-based programs are more willing to [accept subsidized children], because they see it as part of their ministry and ministering to those families."

Some respondents also pointed out that this goal of serving the community could help ensure that faith-based providers continue caring for subsidized children even if they face challenges with the voucher program. A respondent in New Jersey pointed out that faith-based providers' service goals can make them more "amenable to putting up with a lot of the aggravation of being involved in the voucher program." A faith-based provider in California also believed that reminding faith-based providers of their mission could encourage them to participate in the subsidy program:

I hear that it [the subsidy program] is a headache-the red tape, the paperwork, the lack of payment and the time frame [for payments] - those are very strong debates for the other side not to participate [in the subsidy program]. It's only when you can get them past those emotions and those intellectual true facts to what our mission is as Christians and reminding them that these are the children that we're really supposed to be serving.

Another faith-based center director in Washington said the center had to limit the number of children with vouchers it enrolled because its budget could not absorb the lost funds. She noted, however, that the center thought serving subsidized children was important and said, "I look at that amount [the number of subsidized children enrolled] as basically our tithe, our 10 percent that we can give."

\section{Summary and Conclusions}

This analysis offers new insights into the role of faith-based organizations in child care overall and, more specifically, in serving children whose fees are subsidized with vouchers. Although these data from five counties across the country do not provide a nationally representative picture, they do provide a useful glimpse into the nature and variety of the connections between the child care voucher system, faith-based organizations, and religious instruction. Some key findings are summarized below by research question. 


\section{What is the role of faith- based organizations in providing or supporting center- based child care?}

- Faith-based child care appears to play an important role in the child care systems of the five counties we studied. In four counties, approximately one-quarter to one-third of child care centers had an affiliation with an FBO, were housed in a building that belonged to an $\mathrm{FBO}$, or provided religious instruction or organized prayer or worship services. In one county, two-thirds of child care centers had one or more of these faith connections.

- There is no single way to characterize the nature of the connections between FBOs and child care centers. Some child care centers were affiliated with an FBO, which in some cases also meant that the center received support in the form of administrative or accounting assistance, free or discounted rent or utilities, or cash funding. Other child care centers operated independently from FBOs but were housed in buildings belonging to FBOs. A small number of child care centers were neither affiliated with an FBO nor housed in a building belonging to an FBO but reported providing religious instruction or organized prayers or worship services.

- Communities vary substantially in how and how many child care centers connect with FBOs. Each county looked different when we examined how many centers reported being affiliated with FBOs, housed by FBOs, or providing religious instruction, and in the combinations of these forms of involvement.

\section{To what extent do centers affiliated with faith- based organizations care for children receiving child care vouchers?}

- High rates of voucher involvement among faith-affiliated centers in these counties suggest there are not major barriers to the participation of sectarian providers in the voucher program. In all five counties in the study, a majority of faithaffiliated centers were currently caring for children receiving child care vouchers, or had done so within the 6 months before the data collection.

- In three counties, our data do not allow us to conclude that faith-affiliated centers participate in the voucher system at a different level than centers overall. In one county, faith-affiliated centers were significantly more likely than other centers to care for children receiving vouchers. Finally, in one county, faith-affiliated centers were significantly less likely to be caring for children receiving vouchers. Most of the differential in this county was because of a significantly lower rate of 
voucher receipt in centers affiliated with private religious schools (as opposed to nonschool FBOs).

\section{Do faith- based child care providers face any particular barriers to working with the voucher system?}

- The qualitative data suggest that faith-affiliated providers face few policy barriers to serving children with vouchers based solely on their sectarian status. In all but one county, faith-based providers did not have to meet any special requirements to serve children with vouchers, nor did they face any special rules regarding service delivery. Though the rule was abolished in April 2003 before we conducted our site visits, the one exception was a county that required faithbased centers that chose not to be licensed to certify that they met licensing standards in order to serve children receiving vouchers.

- A few qualitative respondents noted that some faith-based child care centers might be concerned about the intrusion of government into their programs or might mistakenly believe that they cannot provide religious instruction if they serve children receiving vouchers. However, respondents believed that this misunderstanding only exists among some faith-based providers.

- Other potential barriers to involvement in the child care voucher system that were reported during the qualitative interviews are not directly related to a child care center's sectarian orientation or affiliation. Specifically, several respondents noted that smaller faith-based centers may have less administrative capacity or cash flow and therefore face greater challenges to involvement if the paperwork is complicated or payments are irregular. This problem has also been noted for smaller service providers in various fields, and it does not appear to be unique to faith-based providers (Kramer et al. 2005). Consequently, a continued focus on simplifying paperwork, improving the accuracy and timeliness of payments, offering training to providers on managing vouchers, and so forth could be helpful for faith-based providers as well as providers overall. In addition, any efforts that provide technical assistance to smaller providers with less administrative capabilities would be a benefit for faith-based providers with those characteristics.

- Respondents suggested that some faith-based child care centers may be especially motivated to care for children receiving vouchers, and to put up with any related administrative burden, because they may view serving low-income families as part of their ministry-oriented or service-to-community-oriented mission. While non-faith-based providers can also see serving low-income families as part 
of their mission, this motivation may play out somewhat more explicitly or frequently in the faith community.

In conclusion, data from our five counties confirm the general impression that FBOs play an important role in the delivery of child care services. Further, the results indicate that FBOs in these five counties are central in serving families receiving child care vouchers. Our qualitative data suggest few barriers to involvement in the child care voucher system are unique to faith-based child care providers. As is usually the case for any research in the field of child care, however, the results also underscore the enormous variation in how FBOs connect to child care centers within and across communities. As a result, it is difficult to provide a simple characterization of the level and kinds of involvement of FBOs in child care and the voucher program.

The research also raises a number of interesting questions for further exploration, including whether these issues play out differently for different denominations, how different kinds of administrative and financial relationships with large FBOs can affect successful voucher involvement, and how strategies to generally simplify the voucher system could support the involvement of faith-based providers. Exploring these questions, developing a better understanding of the complexities of working with faith-based programs and voucher agencies, and replicating this work in other communities would provide useful insights to inform policy and practice for this important segment of the child care community. 


\section{APPENDIX A}

\section{Child Care Providers and the Child Care Voucher System: An Overview of the Urban Institute Research Project}

his report is one of several produced for the Urban Institute's major study, Child

Care Providers and the Child Care Voucher System. The study explores the following research questions:

1. What are the characteristics and quality of providers in the child care market, and do these vary for providers serving children with vouchers? In other words, do providers who serve children with vouchers differ from those who do not serve children receiving vouchers?

2. What are the experiences of providers in working with the child care voucher system? What are the characteristics of the child care voucher program, policies, and implementation that affect providers?

3. What are the implications of these experiences for providers' ability or willingness to care for children with vouchers, for the quality of care they provide, and for their financial stability? What are the implications of these issues for children and families, and for policymakers?

The study took place in five counties in four states: Jefferson (Birmingham), AL; Hudson (Jersey City), NJ; King (Seattle), WA; and Monterey and San Diego, CA. Data for the study included the following:

- A telephone survey of centers and licensed family child care homes to develop a representative picture of providers in each community, discover how many care for children receiving vouchers, and explore whether providers caring for children with vouchers differ from other providers. The survey was designed and implemented in partnership with Mathematica Policy Research, Inc. (MPR). These data were collected in 2003. 
- Qualitative data collection to develop a rich picture of how voucher programs and policies were implemented and how they were experienced by providers. Data were collected through interviews with state or local subsidy administrators and key experts, focus groups with child care providers (subsidized and unsubsidized) and caseworkers, and reviews of relevant policy documents. These data were collected in early 2004.

We also completed substudies on three additional topics that were not the primary focus of the data collection. First, in three sites, we explored child care voucher policies and implementation practices from the perspective of legally unregulated family, friend, and neighbor caregivers. Second, we assessed the prevalence of faith-based providers in the market for child care and explored their experiences with the voucher system. Finally, we used the center-based survey data to determine how many centers serve children who were, or might be, affected by state prekindergarten initiatives and to describe some key characteristics of these centers.

When completed, the following six reports from the study may be downloaded from http://www.urban.org:

- Centers and Family Child Care Homes Caring for Children Receiving Publicly Funded Vouchers: A Descriptive Study in Five Counties, by Rohacek and Kisker

- Child Care Voucher Programs: Provider Experiences in Five Counties, by Adams, Rohacek, and Snyder

- Exploring Child Care Provider Involvement with Voucher Programs and Potential Implications for Financial Well-Being and Quality, by Adams and Rohacek

- Child Care Vouchers and Unregulated Family, Friend, and Neighbor Care, by Snyder, Bernstein, and Adams

- Prekindergarten Programs and Community-Based Child Care: Exploring Challenges and Opportunities through Characteristics of Centers in Five Counties, by Rohacek and Adams

- Child Care Centers, Child Care Vouchers, and Faith-Based Organizations, by Rohacek, Adams, and Snyder 


\section{APPENDIX B}

\section{Data Tables}

r

his appendix contains complete tabular results and additional statistical details for the findings reported in the main text. The data tables include the following information for each county.

- Percentage of centers with the characteristic being described.

- 90 percent confidence interval around the estimate of the percent of centers with the characteristic. The 90 percent confidence interval describes the range within which we are reasonably confident that the true population value falls. ${ }^{16}$ In addition, by observing whether the confidence intervals for subgroups overlap, the intervals may be used to assess whether observed differences between sampled groups are likely to result from sampling error.

- Standard error of the point estimate. This measures the precision of the point estimate and is directly related to the confidence interval.

- The p-values, the bottom-line result of significance tests for differences between subgroups. The $p$-value gives the probability of observing differences at least as big as those observed if no difference actually exists. The tables typically include $p$-values from an overall test of equality of estimates across the five counties and from tests for equality of estimates between each pair of counties. In addition, one variable includes results of a test for equality of the estimates across two groups of providers within each county.

- $n$, the number of cases responding to the question. The question-specific sample size may differ from the overall sample size owing to item nonresponse or use of a subset of the sample for the analysis.

See appendix $C$ for additional methodological details. 
TABLE B1. Centers Affiliated with Any Type of Faith- Based Organization, and with a Private Religious School versus Nonschool Faith- Based Organization, 2003

\begin{tabular}{|c|c|c|c|c|c|c|c|c|c|c|c|c|c|c|c|}
\hline \multirow[b]{2}{*}{ County } & \multicolumn{5}{|c|}{$\begin{array}{c}\text { Affiliated with } \\
\text { Any Type of FBO }\end{array}$} & \multicolumn{5}{|c|}{$\begin{array}{c}\text { Affiliated with a } \\
\text { Private Religious School }\end{array}$} & \multicolumn{5}{|c|}{$\begin{array}{l}\text { Affiliated with a } \\
\text { Nonschool FBO }\end{array}$} \\
\hline & $\begin{array}{c}\% \text { of } \\
\text { centers }\end{array}$ & \multicolumn{2}{|c|}{$90 \% \mathrm{Cl}$} & SE & $n$ & $\begin{array}{c}\% \text { of } \\
\text { centers }\end{array}$ & $90 \%$ & $\% \mathrm{Cl}$ & SE & $n$ & $\begin{array}{c}\% \text { of } \\
\text { centers }\end{array}$ & \multicolumn{2}{|c|}{$90 \% \mathrm{Cl}$} & SE & $n$ \\
\hline Jefferson & 43.9 & \multicolumn{2}{|c|}{$(36.2-51.9)$} & 4.8 & 93 & 17.0 & $(12.9$ & $9-22.2)$ & 2.8 & 93 & 26.8 & \multicolumn{2}{|c|}{$(20.1-34.9)$} & 4.5 & 93 \\
\hline Hudson & 16.0 & \multicolumn{2}{|c|}{$(10.7-23.4)$} & 3.8 & 83 & 7.4 & $(4.2$ & $2-12.8)$ & 2.5 & 83 & 8.6 & \multicolumn{2}{|c|}{$(4.7-15.4)$} & 3.1 & 83 \\
\hline King & 17.0 & \multicolumn{2}{|c|}{$(11.2-25.1)$} & 4.2 & 92 & 6.2 & $(2.9$ & $9-12.6)$ & 2.8 & 92 & 10.8 & \multicolumn{2}{|c|}{$(6.2-18.1)$} & 3.5 & 92 \\
\hline Monterey & 25.3 & \multicolumn{2}{|c|}{$(22.5-28.3)$} & 1.7 & 47 & 8.3 & $(6.8$ & $8-10.1)$ & 1.0 & 47 & 17.0 & \multicolumn{2}{|c|}{$(14.6-19.7)$} & 1.6 & 47 \\
\hline San Diego & 34.8 & \multicolumn{2}{|c|}{$(27.8-42.6)$} & 4.5 & 92 & 25.0 & (18.8 & $8-32.4)$ & 4.1 & 92 & 9.8 & \multicolumn{2}{|c|}{$(6.0-15.6)$} & 2.8 & 92 \\
\hline$p$-value ${ }^{\mathrm{a}}$ & .000 & & & & & .000 & & & & & .002 & & & & \\
\hline $\begin{array}{l}\text { Pairwise } \\
p \text {-values } \\
\end{array}$ & Huds. & King & Mont. & $\begin{array}{c}\text { San } \\
\text { Diego }\end{array}$ & & Huds. & King & Mont. & $\begin{array}{c}\text { San } \\
\text { Diego }\end{array}$ & & Huds. & King & Mont. & $\begin{array}{c}\text { San } \\
\text { Diego } \\
\end{array}$ & \\
\hline Jefferson & .000 & .000 & .000 & .173 & & .011 & .006 & .004 & .112 & & .001 & .005 & .039 & .002 & \\
\hline Hudson & & .860 & .029 & .002 & & & .745 & $\mathrm{n} / \mathrm{c}$ & .000 & & & .638 & $\mathrm{n} / \mathrm{c}$ & .774 & \\
\hline King & & & .071 & .004 & & & & $\mathrm{n} / \mathrm{c}$ & .000 & & & & .113 & .824 & \\
\hline Monterey & & & & .051 & & & & & .000 & & & & & .028 & \\
\hline
\end{tabular}

Source: The Urban Institute, 2008.

$\mathrm{FBO}=$ faith- based organization

$\mathrm{Cl}=$ confidence interval

$\mathrm{SE}=$ standard error

$\mathrm{n} / \mathrm{c}=$ not calculated, more than 20 percent of cells had less than five expected observations

Notes: Confidence intervals may be used in lieu of $\mathrm{n} / \mathrm{c}$ tests of significance to assess the likelihood that observed differences across the groups result from sampling error rather than actual differences in the population.

Standard errors and related confidence intervals account for the sample design and use a finite population correction factor.

$p$ - values are not adjusted to account for multiple tests.

$p$ - values are italicized if $p<.10$, the threshold for significance used in the report text.

a $p$-value shows result of test hypothesizing that the population values are equal across all five counties.

${ }^{b} p$-values show results of each (pairwise) test hypothesizing that the population values for the pair of counties are equal. 
TABLE B2. Centers Affiliated with a Private Religious School, among Centers Affiliated with a Faith- Based Organization, 2003

\begin{tabular}{|c|c|c|c|c|c|c|c|c|}
\hline \multirow[b]{2}{*}{ County } & \multirow[b]{2}{*}{$\begin{array}{l}\% \text { of affili- } \\
\text { ated cente }\end{array}$} & \multirow[b]{2}{*}{$90 \% \mathrm{Cl}$} & \multirow[b]{2}{*}{ SE } & \multirow[b]{2}{*}{$n$} & \multicolumn{4}{|c|}{ Pairwise $p$-values ${ }^{a}$} \\
\hline & & & & & Huds. & King & Mont. & $\begin{array}{l}\text { San } \\
\text { Diego }\end{array}$ \\
\hline Jefferson & 38.8 & $(29.6-48.9)$ & 5.9 & 49 & .614 & .872 & .403 & .001 \\
\hline Hudson & 46.3 & $(26.1-67.7)$ & 13.4 & 12 & & .611 & .342 & $n / c$ \\
\hline King & 36.4 & $(17.4-60.7)$ & 14.0 & 11 & & & $\mathrm{n} / \mathrm{c}$ & $n / c$ \\
\hline Monterey & 33.0 & $(27.2-39.3)$ & 3.7 & 12 & & & & $n / c$ \\
\hline San Diego & 71.8 & $(58.2-82.3)$ & 7.4 & 32 & & & & \\
\hline$p$-value ${ }^{b}$ & .001 & & & & & & & \\
\hline
\end{tabular}

Source: The Urban Institute, 2008.

$\mathrm{Cl}=$ confidence interval

$\mathrm{SE}=$ standard error

$\mathrm{n} / \mathrm{c}=$ not calculated, more than 20 percent of cells had less than five expected observations

Notes: Confidence intervals may be used in lieu of $\mathrm{n} / \mathrm{c}$ tests of significance to assess the likelihood that observed differences across the groups result from sampling error rather than actual differences in the population.

Standard errors and related confidence intervals account for the sample design and use a finite population correction factor. $p$-values are not adjusted to account for multiple tests.

$p$-values are italicized if $p<.10$, the threshold for significance used in the report text.

a $p$-values show results of each (pairwise) test hypothesizing that the population values for the pair of counties are equal.

${ }^{\mathrm{b}} p$-value shows result of test hypothesizing that the population values are equal across all five counties. 
TABLE B3. Centers Receiving Various Types of Assistance from Faith- Based Organizations, among Centers Affiliated with a Faith- Based Organization, 2003

\begin{tabular}{|c|c|c|c|c|c|c|c|c|c|c|c|c|}
\hline \multirow[b]{2}{*}{ County } & \multicolumn{4}{|c|}{ Receiving Cash Assistance } & \multicolumn{4}{|c|}{$\begin{array}{l}\text { Receiving Administrative } \\
\text { or Accounting Support }\end{array}$} & \multicolumn{4}{|c|}{$\begin{array}{l}\text { Receiving Discounted/ } \\
\text { Free Rent or Utilities }\end{array}$} \\
\hline & $\begin{array}{l}\% \text { of affili- } \\
\text { ated cente }\end{array}$ & $90 \% \mathrm{Cl}$ & SE & $n$ & $\begin{array}{l}\% \text { of affili- } \\
\text { ated centers }\end{array}$ & $90 \% \mathrm{Cl}$ & SE & $n$ & $\begin{array}{l}\% \text { of affili- } \\
\text { ated centers }\end{array}$ & $90 \% \mathrm{Cl}$ & SE & $n$ \\
\hline Jefferson & 16.6 & $(7.4-32.9)$ & 7.6 & 22 & 33.1 & $(19.4-50.5)$ & 9.7 & 22 & 50.9 & $(34.6-67.0)$ & 10.2 & 23 \\
\hline Hudson & 0.0 & $(0.0-40.1)$ & $\mathrm{n} / \mathrm{c}$ & 5 & 40.0 & $(13.7-73.7)$ & 20.9 & 5 & 20.0 & $(4.1-59.1)$ & 17.1 & 5 \\
\hline King & 28.6 & $(9.2-61.1)$ & 17.0 & 7 & 42.9 & $(17.7-72.3)$ & 18.6 & 7 & 42.9 & $(17.7-72.3)$ & 18.6 & 7 \\
\hline Monterey & 25.0 & $(17.8-33.9)$ & 4.9 & 8 & 87.9 & $(83.1-91.5)$ & 2.5 & 8 & 63.8 & $(59.5-67.8)$ & 2.5 & 8 \\
\hline San Diego & 30.8 & $(18.0-47.5)$ & 9.2 & 9 & 52.9 & $(35.6-69.5)$ & 10.7 & 9 & 76.4 & $(49.5-91.5)$ & 13.1 & 9 \\
\hline
\end{tabular}

Source: The Urban Institute, 2008.

$\mathrm{Cl}=$ confidence interval

$\mathrm{SE}=$ standard error

$\mathrm{n} / \mathrm{c}=$ not calculated, no variation in sample responses

Notes: Results for significance tests ( $p$-values) are not reported because for all tests, more than 20 percent of cells had less than five expected observations.

Confidence intervals may be used in lieu of tests of significance to assess the likelihood that observed differences across the groups result from sampling error rather than actual differences in the population.

Confidence intervals for $\mathrm{n}$ / c standard errors are based on the adjusted Wald interval (Agresti and Coull 1998).

Standard errors and related confidence intervals account for the sample design and use a finite population correction factor. 


\section{TABLE B4. Centers that Are Faith- Housed (Reside in Space Belonging to a Faith- Based Organization), among All Centers and by Reported Affiliation with a Faith- Based Organization, 2003}

\begin{tabular}{|c|c|c|c|c|c|c|c|c|c|c|c|c|}
\hline \multirow[b]{2}{*}{ County } & \multicolumn{4}{|c|}{ Among All Centers } & \multicolumn{4}{|c|}{$\begin{array}{c}\text { Among Centers } \\
\text { Affiliated with an FBO }\end{array}$} & \multicolumn{4}{|c|}{$\begin{array}{l}\text { Among Centers Not } \\
\text { Affiliated with an FBO }\end{array}$} \\
\hline & $\begin{array}{c}\% \text { of } \\
\text { centers }\end{array}$ & $90 \% \mathrm{Cl}$ & SE & $n$ & $\begin{array}{c}\% \text { of } \\
\text { centers }\end{array}$ & $90 \% \mathrm{Cl}$ & SE & $n$ & $\begin{array}{c}\% \text { of } \\
\text { centers }\end{array}$ & $90 \% \mathrm{Cl}$ & SE & $n$ \\
\hline Jefferson & 41.3 & $(33.7-49.3)$ & 4.8 & 93 & 82.1 & $(70.3-89.8)$ & 5.9 & 49 & 9.5 & $(4.4-19.0)$ & 4.2 & 44 \\
\hline Hudson & 26.8 & $(20.1-34.8)$ & 4.5 & 83 & 78.5 & $(52.8-92.3)$ & 12.0 & 12 & 17.0 & $(11.3-24.7)$ & 4.0 & 71 \\
\hline King & 19.2 & $(13.1-27.2)$ & 4.3 & 92 & 81.8 & $(56.3-94.0)$ & 11.2 & 11 & 6.3 & $(3.2-12.1)$ & 2.6 & 81 \\
\hline Monterey & 27.3 & $(24.6-30.3)$ & 1.8 & 47 & 91.9 & $(88.6-94.3)$ & 1.7 & 12 & 5.5 & $(4.3-6.9)$ & 0.8 & 35 \\
\hline San Diego & 37.0 & $(29.8-44.8)$ & 4.6 & 92 & 97.1 & $(87.9-99.4)$ & 2.6 & 32 & 4.9 & $(2.1-11.1)$ & 2.5 & 60 \\
\hline$p$-value ${ }^{\mathrm{a}}$ & .004 & & & & $\mathrm{n} / \mathrm{c}$ & & & & .075 & & & \\
\hline
\end{tabular}

\begin{tabular}{|c|c|c|c|c|c|c|c|c|c|c|c|c|}
\hline $\begin{array}{l}\text { Pairwise } \\
p \text {-values }{ }^{\text {b }}\end{array}$ & Huds. & King & Mont. & $\begin{array}{c}\text { San } \\
\text { Diego }\end{array}$ & Huds. & King & Mont. & $\begin{array}{c}\text { San } \\
\text { Diego }\end{array}$ & Huds. & King & Mont. & $\begin{array}{c}\text { San } \\
\text { Diego }\end{array}$ \\
\hline Jefferson & .028 & .001 & .006 & .515 & $\mathrm{n} / \mathrm{c}$ & $\mathrm{n} / \mathrm{c}$ & $\mathrm{n} / \mathrm{c}$ & $n / c$ & .198 & $\mathrm{n} / \mathrm{c}$ & $\mathrm{n} / \mathrm{c}$ & $n / c$ \\
\hline Hudson & & .217 & .917 & .115 & & $n / c$ & $n / c$ & $\mathrm{n} / \mathrm{c}$ & & .027 & .006 & .012 \\
\hline King & & & .079 & .005 & & & $\mathrm{n} / \mathrm{c}$ & $n / c$ & & & $\mathrm{n} / \mathrm{c}$ & $n / c$ \\
\hline Monterey & & & & .051 & & & & $n / c$ & & & & $\mathrm{n} / \mathrm{c}$ \\
\hline
\end{tabular}

Source: The Urban Institute, 2008.

$\mathrm{FBO}=$ faith- based organization

$\mathrm{Cl}=$ confidence interval

$\mathrm{SE}=$ standard error

$\mathrm{n} / \mathrm{c}=$ not calculated, more than 20 percent of cells had less than 5 expected observations

Notes: Confidence intervals may be used in lieu of $\mathrm{n} / \mathrm{c}$ tests of significance to assess the likelihood that observed differences across the groups result from sampling error rather than actual differences in the population.

Standard errors and related confidence intervals account for the sample design and use a finite population correction factor. $p$-values are not adjusted to account for multiple tests.

$p$-values are italicized if $p<.10$, the threshold for significance used in the report text

a $p$-value shows result of test hypothesizing that the population values are equal across all five counties.

b $p$-values show results of each (pairwise) test hypothesizing that the population values for the pair of counties are equal. 
TABLE B5. Faith- Infused Centers (Provide Religious Instruction, or Organized Prayers or Worship Services), among All Centers and by Affiliation with a Faith- Based Organization and by Whether Center Is Housed by a Faith- Based Organization, 2003

\begin{tabular}{|c|c|c|c|c|c|c|c|c|c|c|c|c|}
\hline \multirow[b]{2}{*}{ County } & \multicolumn{4}{|c|}{ Among All Centers } & \multicolumn{4}{|c|}{$\begin{array}{c}\text { Among Centers } \\
\text { Affiliated with an FBO }\end{array}$} & \multicolumn{4}{|c|}{$\begin{array}{c}\text { Among Centers Not } \\
\text { Affiliated with an FBO }\end{array}$} \\
\hline & $\begin{array}{c}\% \text { of } \\
\text { centers }\end{array}$ & $90 \% \mathrm{Cl}$ & SE & $n$ & $\begin{array}{c}\% \text { of } \\
\text { centers }\end{array}$ & $90 \% \mathrm{Cl}$ & SE & $n$ & $\begin{array}{c}\% \text { of } \\
\text { centers }\end{array}$ & $90 \% \mathrm{Cl}$ & SE & $n$ \\
\hline Jefferson & 54.4 & $(46.1-62.5)$ & 5.0 & 92 & 72.2 & $(59.6-82.0)$ & 6.8 & 49 & 40.1 & $(29.1-52.2)$ & 7.1 & 43 \\
\hline Hudson & 10.9 & $(6.6-17.3)$ & 3.2 & 83 & 64.3 & $(40.4-82.6)$ & 13.5 & 12 & 0.7 & $(0.3-1.3)$ & 0.3 & 71 \\
\hline King & 14.0 & $(8.8-21.5)$ & 3.8 & 92 & 63.6 & $(39.1-82.7)$ & 14.0 & 11 & 3.8 & $(1.7-8.5)$ & 1.9 & 81 \\
\hline Monterey & 25.3 & $(22.5-28.3)$ & 1.7 & 47 & 100.0 & $(78.4-100.0)$ & $\mathrm{n} / \mathrm{c}$ & 12 & 0.0 & $(0.0-8.6)$ & $n / c$ & 35 \\
\hline San Diego & 28.0 & $(21.6-35.5)$ & 4.3 & 92 & 80.5 & $(67.7-89.0)$ & 6.4 & 32 & 0.0 & $(0.0-5.2)$ & $\mathrm{n} / \mathrm{c}$ & 60 \\
\hline$p$-value $\mathrm{e}^{\mathrm{a}}$ & .000 & & & & $n / c$ & & & & $n / c$ & & & \\
\hline
\end{tabular}

\begin{tabular}{|c|c|c|c|c|c|c|c|c|c|c|c|c|}
\hline $\begin{array}{l}\text { Pairwise } \\
p \text {-values }{ }^{b}\end{array}$ & Huds. & King & Mont. & $\begin{array}{c}\text { San } \\
\text { Diego }\end{array}$ & Huds. & King & Mont. & $\begin{array}{c}\text { San } \\
\text { Diego }\end{array}$ & Huds. & King & Mont. & $\begin{array}{l}\text { San } \\
\text { Diego }\end{array}$ \\
\hline Jefferson & .000 & .000 & .000 & .000 & $n / c$ & $n / c$ & $n / c$ & .376 & .000 & .000 & .000 & .000 \\
\hline Hudson & & .525 & .000 & .001 & & $n / c$ & $n / c$ & $n / c$ & & $n / c$ & $n / c$ & $\mathrm{n} / \mathrm{c}$ \\
\hline King & & & .007 & .014 & & & $n / c$ & $n / c$ & & & $n / c$ & $\mathrm{n} / \mathrm{c}$ \\
\hline Monterey & & & & .553 & & & & $n / c$ & & & $x_{0}$ & $n / c$ \\
\hline
\end{tabular}

\begin{tabular}{|c|c|c|c|c|c|c|c|c|}
\hline \multirow[b]{2}{*}{ County } & \multicolumn{4}{|c|}{$\begin{array}{l}\text { Among Centers } \\
\text { Housed by an FBO }\end{array}$} & \multicolumn{4}{|c|}{$\begin{array}{l}\text { Among Centers Not } \\
\text { Housed by an FBO }\end{array}$} \\
\hline & $\begin{array}{c}\% \text { of } \\
\text { centers }\end{array}$ & $90 \% \mathrm{Cl}$ & SE & $n$ & $\begin{array}{c}\% \text { of } \\
\text { centers }\end{array}$ & $90 \% \mathrm{Cl}$ & SE & $n$ \\
\hline Jefferson & 83.3 & $(70.6-91.2)$ & 6.1 & 46 & 33.5 & $(23.5-45.3)$ & 6.7 & 46 \\
\hline Hudson & 31.9 & $(18.6-49.1)$ & 9.4 & 23 & 3.1 & $(1.1-8.9)$ & 2.0 & 60 \\
\hline King & 67.4 & $(46.1-83.3)$ & 11.7 & 15 & 1.3 & $(0.6-3.1)$ & 0.7 & 77 \\
\hline Monterey & 85.0 & $(81.3-88.1)$ & 2.1 & 13 & 2.8 & $(2.0-4.0)$ & 0.6 & 34 \\
\hline San Diego & 75.8 & $(63.0-85.2)$ & 6.7 & 34 & 0.0 & $(0.0-5.3)$ & $\mathrm{n} / \mathrm{c}$ & 58 \\
\hline$p$-value ${ }^{a}$ & .000 & & & & $n / c$ & & & \\
\hline
\end{tabular}

\begin{tabular}{|c|c|c|c|c|c|c|c|c|}
\hline $\begin{array}{l}\text { Pairwise } \\
p \text {-values }^{\text {b }}\end{array}$ & Huds. & King & Mont. & $\begin{array}{c}\text { San } \\
\text { Diego }\end{array}$ & Huds. & King & Mont. & $\begin{array}{c}\text { San } \\
\text { Diego }\end{array}$ \\
\hline Jefferson & .000 & $\mathrm{n} / \mathrm{c}$ & $\mathrm{n} / \mathrm{c}$ & .412 & .000 & .000 & .000 & .000 \\
\hline Hudson & & .020 & .000 & .000 & & $\mathrm{n} / \mathrm{c}$ & $n / c$ & $n / c$ \\
\hline King & & & $n / c$ & $n / c$ & & & $n / c$ & $n / c$ \\
\hline Monterey & & & & $\mathrm{n} / \mathrm{c}$ & & & & $n / c$ \\
\hline
\end{tabular}

Source: The Urban Institute, 2008.

$\mathrm{FBO}=$ faith- based organization

$\mathrm{Cl}=$ confidence interval

$\mathrm{SE}=$ standard error

$\mathrm{n} / \mathrm{c}=$ not calculated, no variation in sample responses (standard error) or more than 20 percent of cells had less than five expected observations ( $p$-value)

Notes: Confidence intervals may be used in lieu of $\mathrm{n} / \mathrm{c}$ tests of significance to assess the likelihood that observed differences across groups result from sampling error rather than actual differences in the population.

Confidence intervals for $\mathrm{n} / \mathrm{c}$ standard errors are based on the adjusted Wald interval (Agresti and Coull 1998).

Standard errors and confidence intervals account for sample design and use a finite population correction factor.

$p$-values were not adjusted to account for multiple tests.

$p$-values are italicized if $p<.10$, the threshold for significance used in the report text.

a $p$-value shows result of test hypothesizing that the population values are equal across all five counties.

${ }^{b} p$-values show results of each (pairwise) test hypothesizing that the population values for the pair of counties are equal. 
TABLE B6. Centers with Any Connection to a Faith- Based Organization (Faith- Affiliated, Faith- Housed, and/ or Faith- Infused), 2003

\begin{tabular}{|c|c|c|c|c|c|c|c|c|}
\hline \multirow[b]{2}{*}{ County } & \multirow[b]{2}{*}{$\begin{array}{c}\% \text { of } \\
\text { centers }\end{array}$} & \multirow[b]{2}{*}{$90 \% \mathrm{Cl}$} & \multirow[b]{2}{*}{ SE } & \multirow[b]{2}{*}{$n$} & \multicolumn{4}{|c|}{ Pairwise $p$-values ${ }^{a}$} \\
\hline & & & & & Huds. & King & Mont. & $\begin{array}{c}\text { San } \\
\text { Diego }\end{array}$ \\
\hline Jefferson & 67.3 & $(59.0-74.7)$ & 4.8 & 92 & .000 & .000 & .000 & .000 \\
\hline Hudson & 30.8 & $(23.7-39.0)$ & 4.7 & 83 & & .252 & .772 & .278 \\
\hline King & 23.4 & $(16.7-31.7)$ & 4.6 & 92 & & & .217 & .025 \\
\hline Monterey & 29.4 & $(26.6-32.4)$ & 1.8 & 47 & & & & .083 \\
\hline San Diego & 38.0 & $(30.7-45.9)$ & 4.6 & 92 & & & & \\
\hline$p$-value $\mathrm{e}^{\mathrm{b}}$ & .000 & & & & & & & \\
\hline
\end{tabular}

Source: The Urban Institute, 2008.

$\mathrm{Cl}=$ confidence interval

$\mathrm{SE}=$ standard error

Notes: Standard errors and related confidence intervals account for the sample design and use a finite population correction factor.

$p$ - values were not adjusted to account for multiple tests.

$p$ - values are italicized if $p<.10$, the threshold for significance used in the report text.

${ }^{a} p$ - values show results of each (pairwise) test hypothesizing that the population values for the pair of counties are equal.

${ }^{\mathrm{b}} p$-value shows result of test hypothesizing that the population values are equal across all five counties. 
TABLE B7. Centers Currently or Recently Caring for at Least One Child with a Voucher, by Reported Affiliation with a Faith- based Organization, and by Reported Affiliation with a Private Religious School or Nonschool Faith- Based Organization, 2003

\begin{tabular}{|c|c|c|c|c|c|c|c|c|c|}
\hline \multirow[b]{2}{*}{ County } & \multicolumn{4}{|c|}{$\begin{array}{l}\text { Among Centers Not } \\
\text { Affiliated with an FBO }\end{array}$} & \multicolumn{4}{|c|}{$\begin{array}{c}\text { Among Centers } \\
\text { Affiliated with an FBO }\end{array}$} & \multirow[b]{2}{*}{$p$-value } \\
\hline & $\begin{array}{c}\% \text { of } \\
\text { centers }\end{array}$ & $90 \% \mathrm{Cl}$ & SE & $n$ & $\begin{array}{c}\% \text { of } \\
\text { centers }\end{array}$ & $90 \% \mathrm{Cl}$ & SE & $n$ & \\
\hline Jefferson & 94.8 & $(93.0-96.2)$ & 9.6 & 44 & 69.2 & $(63.0-74.8)$ & 3.6 & 49 & .000 \\
\hline Hudson & 81.7 & $(74.6-87.2)$ & 3.8 & 71 & 89.5 & $(82.5-93.9)$ & 3.3 & 12 & $n / c$ \\
\hline King & 79.3 & $(75.0-83.1)$ & 2.4 & 81 & 100.0 & $(76.9-100.0)$ & $n / c$ & 11 & $\mathrm{n} / \mathrm{c}$ \\
\hline Monterey & 62.1 & $(58.1-65.9)$ & 2.3 & 35 & 74.0 & $(67.1-79.9)$ & 8.3 & 12 & $\mathrm{n} / \mathrm{c}$ \\
\hline San Diego & 70.3 & $(62.4-77.2)$ & 4.5 & 60 & 61.9 & $(49.9-72.6)$ & 6.9 & 32 & .367 \\
\hline
\end{tabular}

\begin{tabular}{|c|c|c|c|c|c|c|c|c|c|c|c|c|c|}
\hline \multirow[b]{2}{*}{ County } & \multicolumn{4}{|c|}{$\begin{array}{l}\text { Among Centers Not } \\
\text { Affiliated with an FBO }\end{array}$} & \multicolumn{4}{|c|}{$\begin{array}{l}\text { Among Centers Affiliated with } \\
\text { a Private Religious School }\end{array}$} & \multicolumn{4}{|c|}{$\begin{array}{l}\text { Among Centers Affiliated } \\
\text { with a Nonschool FBO }\end{array}$} & \multirow[b]{2}{*}{$p$-value ${ }^{b}$} \\
\hline & $\begin{array}{c}\% \text { of } \\
\text { centers }\end{array}$ & $90 \% \mathrm{Cl}$ & SE & $n$ & $\begin{array}{l}\% \text { of } \\
\text { centers }\end{array}$ & $90 \% \mathrm{Cl}$ & SE & $n$ & $\begin{array}{c}\% \text { of } \\
\text { centers }\end{array}$ & $90 \% \mathrm{Cl}$ & SE & $n$ & \\
\hline Jefferson & 94.8 & $(93.0-96.2)$ & 9.6 & 44 & 46.2 & $(32.1-61.0)$ & 8.9 & 26 & 83.8 & $(77.7-88.6)$ & 3.3 & 23 & .000 \\
\hline Hudson & 81.7 & $(74.6-87.2)$ & 37.8 & 71 & 77.3 & $(59.9-88.6)$ & 8.7 & 7 & 100.0 & (59.9-100.0) & $n / c$ & 5 & $\mathrm{n} / \mathrm{c}$ \\
\hline King & 79.3 & $(75.0-83.1)$ & 2.4 & 81 & 100.0 & $(54.3-100.0)$ & $\mathrm{n} / \mathrm{c}$ & 4 & 100.0 & $(67.8-100.0)$ & $n / c$ & 7 & $n / c$ \\
\hline Monterey & 62.1 & $(58.1-65.9)$ & 2.3 & 35 & 73.7 & $(61.1-83.3)$ & 6.7 & 4 & 74.2 & $(65.3-81.4)$ & 4.8 & 8 & $\mathrm{n} / \mathrm{c}$ \\
\hline San Diego & 70.3 & $(62.4-77.2)$ & 4.5 & 60 & 63.1 & $(48.1-75.9)$ & 8.6 & 23 & 58.9 & $(35.3-79.0)$ & 14.1 & 9 & .650 \\
\hline
\end{tabular}

Source: The Urban Institute, 2008

$\mathrm{FBO}=$ faith- based organization

$\mathrm{Cl}=$ confidence interval

$\mathrm{SE}=$ standard error

$\mathrm{n} / \mathrm{c}=$ not calculated, no variation in sample responses (standard error) or more than 20 percent of cells had less than five expected observations ( $p$-value)

Notes: Confidence intervals may be used in lieu of $\mathrm{n} / \mathrm{c}$ tests of significance to assess the likelihood that observed differences across the groups result from sampling error rather than actual differences in the population.

Confidence intervals for $\mathrm{n} / \mathrm{c}$ standard errors are based on the adjusted Wald interval (Agresti and Coull 1998).

Standard errors and related confidence intervals account for the sample design and use a finite population correction factor.

$p$-values were not adjusted to account for multiple tests.

$p$-values were not adjusted to account for multiple tests.
$p$ - values are italicized if $p<.10$, the threshold for significance used in the report text.

- values are ilalicized if $p<.10$, the threshold for significance used in the report text.

$p$ - value shows result of

$p$-value shows result of test hypothesizing that the population values for the three groups (not affilated, affilated with a private religious school and affilated
with a nonschool FBO) within the county are equal. 


\title{
APPENDIX C
}

\section{Analytic Methods}

\begin{abstract}
A nalysis was carried out using version 9 of Stata statistical software (StataCorp 2005a). Stata's survey (svy) commands were used to incorporate sample design information (including weights, sampling strata, and finite population correction factors) into the standard errors and related statistics for the weighted point estimates. To ensure adequate representation of subsidized and unsubsidized providers in each county, sampling frames were stratified by subsidy status before sample section. Stratum-specific weights were applied to adjust for probability of selection into the sample and for survey nonresponse. The finite population correction factor was used to adjust the standard error for the share of the population in each county that was included in the sample. The finite population correction made the greatest improvement in the precision of estimates in Monterey County, where the full population of centers in the sampling frame was sampled (and therefore the only variance results from survey non-response). The finite population correction made the smallest difference for precision in San Diego and King counties, where only about a quarter of centers in the sampling population were selected for the sample.
\end{abstract}

Most results are based on the default options for the svy: tabulate commands that are documented in the Stata Survey Data Reference Manual (StataCorp 2005b). The tests for equality of estimates across counties or other subgroups within counties, however, are based on the adjusted Wald test of independence (StataCorp 2005b). In addition, when all or none of the centers in a given county had a particular characteristic, the Stata svy commands did not permit calculation of a confidence interval for that county. In those cases, for simplicity, an unweighted adjusted Wald binomial confidence interval was estimated instead (Agresti and Coull 1998).

The adjusted Wald test of independence may not be not valid when, under an assumption of independence, any cells have less than one expected case or when more than 20 percent of cells have less than five expected cases. Consequently, statistical tests for independence were not conducted when tests met those conditions. Even without tests for significance, it is possible to calculate confidence intervals for those estimates and to use the intervals to assess how confident we may be that observed differences be- 
tween those groups and others actually result from population differences (rather than sampling error).

To thoroughly explore possible differences across counties and subgroups of providers, the analysis includes a large number of statistical tests. As the number of related statistical tests increases, there is an increased probability of, on at least one test, mistakenly finding a significant difference when one does not exist (Type I error). Analytic techniques exist to maintain a more consistent limit on this type of error across each of the families of tests that are carried out (Keselman, Cribbie, and Holland 2004). However, because those techniques also work to increase the chance that an individual test will not show a significant difference when one exists (Type II error) and because the techniques add to the complexity of analysis, reporting, and interpretation, there is some debate about the appropriateness of those methods for certain types of research (Ahmed 1992; Moran 2003; Roback and Askins 2003; Saville 2003). Since this is an exploratory study designed to highlight areas in which there is some evidence of differences that should be confirmed with future research, we did not make corrections to account for the multiplicity of tests. Although there is a somewhat greater risk than implied by our chosen alpha level that some of the observed statistically significant differences are the result of chance, we determined that this level of risk was acceptable to better ensure that real and potentially important differences were not overlooked. 


\section{Notes}

1. The overall response rate for centers on the survey was 82 percent, with response rates in individual counties ranging from 79 to 92 percent.

2. To ensure adequate representation of providers caring for, and not caring for, children receiving vouchers, sampling frames were stratified by voucher receipt before sample selection. Weights differ across these strata and across counties.

3. This standard for significance ( $p$-value) does, however, increase the risk of finding a difference observed in the sample to be "significant" when a difference does not, in fact, exist in the population.

4. This large level of uncertainty results from small sample sizes. Although the results generally indicate that faith-based centers play a substantial role in the child care system, faith-based providers were sampled in proportion to their prevalence in the population. As a result of this, and our relatively small sample sizes overall, we surveyed a relatively small number of faith-based centers in most of the five counties. This affects the precision of our estimates, especially when looking at subgroups of faith-based providers (such as only those affiliated with faith-based organizations that do not operate a school or only those housed in a building that belongs to a faith-based organization).

5. A 90 percent confidence interval indicates that, if samples were repeatedly drawn and repeated confidence intervals were constructed, approximately 90 percent of the intervals would contain the true population value. For ease, a 90 percent confidence interval may be loosely interpreted as having an approximately 90 percent chance that the interval contains the true population value.

6. If some respondents interpreted being housed in a building belonging to a faith-based organization (without any other connection) as an "affiliation," then our results may slightly overestimate the number of programs that are directly or indirectly operated by faith-based organizations.

7. The survey question asked, "Is your program affiliated with a private religious school, church, synagogue, temple, mosque, or other faith-based organization or group?" Interviewers probed respondents answering yes to determine whether the affiliation was with a private religious school or with a church, synagogue, temple, mosque, or other faith-based organization that does not operate a school.

8. These programs included child care vouchers administered by Child Care Resources (Jefferson County, AL); CalWORKs Stages 1, 2, and 3, and the Alternative Payment programs administered by County Departments of Health and Human Services, Children's Services International, Child Development Associates, and the YMCA Childcare Resource Service (Monterey and San Diego counties, CA); New Jersey Cares for Kids and Work First New Jersey Child Care administered by The Urban League (Hudson County, NJ); and Working Connections Child Care administered by the Department of Social and Health Services (King County, WA).

9. In addition, although not funded by the CCDF, providers caring for children receiving vouchers through a program sponsored by the City of Seattle were counted as being involved with the voucher program. 
10. Data are only shown for Jefferson County because in the other four counties, sample sizes were small (there were cells with zero expected observations or more than 20 percent of cells had less than five observations expected under an assumption of independence), or there were no significant differences. As a result, in those four counties, we are unable to reach a conclusion about the presence or extent of differences between centers not affiliated with FBOs, centers affiliated with private religious schools, and centers affiliated with nonschool FBOs.

11. Both Alabama and New Jersey have certain exemptions for licensing of faith-based providers. In Alabama, the exemption applies to any faith-based provider; in New Jersey, it is a grandfathered clause (only providers operating before May 16, 1984 may maintain their exemption) so it likely affects fewer providers than in Alabama. The sampling frames in both sites included exempt centers, though respondents told us most faith-based centers in New Jersey are, in fact, licensed, and the sampling frame in New Jersey included fewer exempt centers than in Alabama. Some faith-based centers in Alabama are also voluntarily licensed; we did not determine how many.

12. It would be interesting to examine the particular denominations making up the congregation FBOs across our sites. For example, there is some reason to believe that government intrusion may be of much more concern to certain denominations. Although Bogle (2001a) notes that data on this topic are not available, her informants suggested that "resistance to the use of federal funds for child care is most prevalent among congregations representing particularly conservative denominations .... The fear generally expressed by conservative evangelicals is that, with any government money with (sic) inevitably come government intrusion into religiously based activity, curriculums and hiring practices." On the other hand, Bogle also asks whether the decision to accept public funds has as much to do with "social progressivism" as "conservative theology."

13. U.S. Department of Health and Human Services, Child Care Bureau, "What Congregations Should Know about Federal Funding for Child Care," http:/www.acf.dhhs.gov/programs/ccb/providers/ faithbased.htm.

14. In California, although faith-based providers do not have additional requirements, local agencies need to ensure that the state match to the federal CCDF funding is not used to pay faith-based programs that teach religion. As a consequence, local agencies track the type of funding going to faith-based providers to ensure that state funds are not used for this purpose. This allocation of faith-based providers to the federal funding stream appeared to happen "behind the scenes" and did not appear to be an issue for the faith-based providers we interviewed.

15. While we had no corroboration of such problems from any other sources in this site, one licensed faithbased participant in one of our focus groups felt that the local agency made it more difficult for her center to start caring for children receiving vouchers because she was faith-based. She was eventually approved, but she found the process challenging. Again, it is unclear whether this issue differentially affects faith-based providers. For example, in some sites, certain non-faith-affiliated centers and/or family child care providers thought that the voucher agency sent families to "other programs" or otherwise experienced difficulties navigating various aspects of the voucher system. We were unable to confirm whether this practice did indeed occur.

16. See note 5 . 


\section{References}

Adams, Gina, Monica Rohacek, and Kathy Snyder. 2008. Child Care Voucher Programs: Provider Experiences in Five Counties. Washington, DC: The Urban Institute.

Agresti Alan, and Brent A. Coull. 1998. "Approximate Is Better than 'Exact' for Interval Estimation of Binomial Proportions." The American Statistician 52(2): 119-26.

Ahmed, Susan W. 1992. "Issues Arising in the Application of Bonferroni Procedures in Federal Surveys." In Proceedings of the Section on Survey Research Methods, American Statistical Association. Alexandria VA: American Statistical Association.

Bogle, Mary M. 2001a. “The Role of Faith-Based Organizations in Child Care: Morning Discussion." Transcript from presentation and panel discussion at the Brookings Institution, Washington, D.C., March 14.

- - - 2001b. "A Survey of Congregation-Based Child Care in the United States." In Sacred Places, Civic Purposes: Should Government Help Faith-Based Charity?, edited by E.J. Dionne and Ming Hsu Chen (216-34). Washington, DC: Brookings Institution Press.

Keselman, H.J., Robert A. Cribbie, and Burt Holland. 2004. "Pairwise Multiple Comparison Test Procedures: An Update for Clinical Child and Adolescent Psychologists." Journal of Clinical Child and Adolescent Psychology 33(3): 623-45.

Kinukawa, Akemi, Lina Guzman, and Laura Lippman. 2004. “National Estimates of Child Care and Subsidy Receipt for Children Ages 0 to 6: What Can We Learn from the National Household Education Survey?" Washington, DC: Child Trends.

Kramer, Fredrica, Kenneth Finegold, Carol J. De Vita, and Laura Wherry. 2005. "Federal Policy on the Ground: Faith-Based Organizations Delivering Local Services." Assessing the New Federalism Discussion Paper 05-01. Washington, DC: The Urban Institute. 
Moran, Matthew D. 2003. "Arguments for Rejecting the Sequential Bonferroni in Ecological Studies." Oikos 100(2): 403-405.

Neugebauer, Roger. 2000. "Religious Organizations Taking Proactive Role in Child Care." Child Care Information Exchange May/June: 18-20.

Ragan, Mark, Lisa M. Montiel, and David J. Wright. 2003. "Scanning the Policy Environment for Faith-Based Social Services in the United States: Results of a 50 State Study." Albany, NY: Roundtable on Religion and Social Welfare Policy.

Roback, Paul J., and Robert A. Askins. 2005. "Judicious Use of Multiple Hypothesis Tests." Conservation Biology 19(1): 261-67.

Saville, David J. 2003. "Basic Statistics and the Inconsistency of Multiple Comparison Procedures." Canadian Journal of Experimental Psychology 57(3): 167-75.

StataCorp. 2005a. Stata Statistical Software: Release 9. College Station, TX: StataCorp LP.

---. 2005b. Stata Survey Data Reference Manual: Release 9. College Station, TX: StataCorp LP.

U.S. Department of Health and Human Services. Administration for Children and Families. 1998. "Child Care and Development Fund Final Rule." Federal Register 60(142): 39935-998.

White House, The. 2001. “Unlevel Playing Field: Barriers to Participation by Faith-Based and Community Organizations in Federal Social Services Programs." Washington, DC: The White House.

Witte, Ann Dryden, and Magaly Queralt. 2005. “Assessing the Quality of Child Care Using Longitudinal, Administrative Data: What Can It Tell Us and How Can It Be Used?" Wellesley, MA: Wellesley Child Care Research Partnership. 


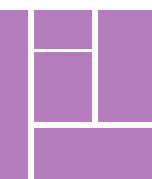

THE URBAN INSTITUTE

Center on Labor, Human Services, and Population 2100 M Street, NW

Washington, DC 20037

www.urban.org

(202) 833-7200 